\title{
النظام البنائي لهيئة الشعاعيات في الطبيعة والافادة منها في التصميم الزخرفي
}

\section{The structural system of the radial body in nature and to benefit from it in the decorative design

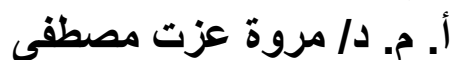

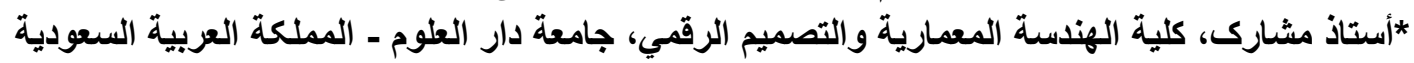

Associ. Prof. Dr. Marwa Ezzat Mostafa

Associate Professor, College of Architecture and Digital Design, Dar Al Uloom

University - Saudi Arabia

marwa.ezzat@dau.edu.sa

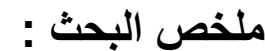

تعد الطبيعة المصدر الرئيسي لاستلهام الفنان و المصمم فهذا الكون المنظم بكل ظو اهرة الطبيعية يخضع لضبط نظامى مرتب بمقاييس وقوانين رياضية تتكرر في النماذج الطبيعية سعيا وراء الاتزان والتناغم والتكيف البيئى، تتمثل هذه المقاييس و القو انين في مجاميع من المنظومات الرقمية، ولقد حفزت الطبيعة ظهور عدة تخصصات مثل النظام الاشعاعي في العناصر الطبيعية الذي بوصفة نظام خارجي ما يتكيف مع البيئة الخارجية من أجل إنجاز وظيفة محددة دون أن يتم توجيهه من الخارج ( بقوة خارجية ) اي تشكل ذاتي ، ومن هنا تحددت مشكلة البحث فى ما مدي امكانية اثر اء فكر المصمم من خلال

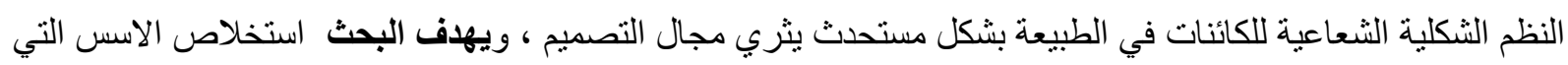
صاغت من خلال النظام الثعاعي للكائنات في الطبيعة والاهتمام بدر اسة البنية الخارجية للاشكال باستخدام الوسائل التكنولوجية الحديثة وتكمن أهمية البحث تكمن أهمية البحث في استخلاص صياغات وتصميمات جديدة من خلال النظم الثعاعية في الطبيعة لابتكارتصميمات تثري مجال التصميم ويفترض البحث ما مدي الاستفادة من النظم البنائية الثكلية للثعاعيات في الطبيعة باستخدام التكنولوجيا الحديثة مما يوسع مدارك المصدم ، وينتهج البحث المنهج الوصفي التحليلي و التجريبي من خلال تتبع الاسس البنائية للشعاعيات في الطبيعة لابتكار تجارب فنبة و تصميمية مستحدثة تثري مجال التصميم ومن نتائج البحث أنه يمكن الربط بين الفن والطبيعة من خلال دراسة الطبيعة التي اضافت مداخل تجريبية وفقًا

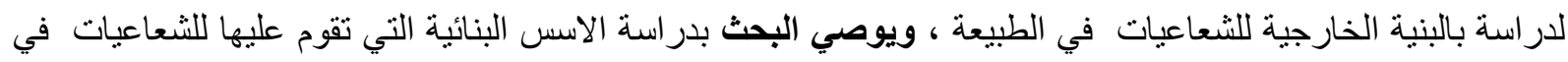

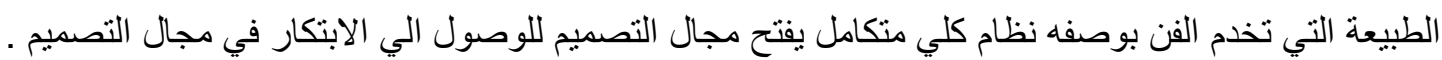
النظام البنائي؛ الشعاعيات في الطبيعة؛ التصميمات الزخرفية

\section{Abstract:}

Nature is the main source of inspiration for the artist and designer. This organized universe in all its natural phenomena is subject to a systemic adjustment arranged by mathematical standards and laws that are repeated in the natural models in pursuit of balance, harmony and environmental adaptation. These measures and laws are represented in groups of digital systems, and nature has stimulated the emergence of several disciplines such as the radiation system In the natural elements that, as an external system, adapts to the external environment in order to accomplish a specific function without being directed from the outside (by an external force) i.e. self-formation, and from here the research problem was determined in the extent of the possibility of richness in the designer's thought through the radial formal systems of objects that were formulated by studying the structural system of organisms in nature and the 
importance of research lies in linking nature with art by studying the external formal structure of the elements in nature and extracting new formulations and designs through radial systems In nature, study of nature that added experimental approaches according to To study the external structure the research recommends studying the structural foundations upon in nature are based, which serve art as an integrated holistic system that opens the field of design to reach innovation in the field of design.

\section{Keywords:}

Design drafts $\lfloor$ Radials in nature $\lfloor$ Decorative designs

ان الطبيعة تتسم بالتشكل و التغير الدائم و المستمرفى مظهر ها المرئى وفقا لما يحدث فى الطبيعة من متغيرات متكررة، ور غم ذللك يطر أ على هذه العناصر متغير ات متنوعة إلا أنه يحكمها قانون الطبيعة الأزلى للنظام البنائي المتغير ، فالكائنات

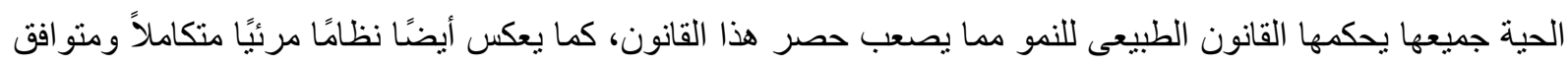
يستخلص منه المصمم و الفنان ليعبر عنه برؤيته الخاصة ووسائل الأدائية في تصميماته المستوحاة من الطبيعة الخارجية "(3) ، فالإنسان بطبعه يميل إلى النظام المستمر ، و هذا يبعث فى ذهنه نوعًا من الارتباح ، " فينذ نشأته الأولى يسعى دائمًا إلى النظام و الترتيب فى مختلف مظاهر حياته، فيستخدم قدر اته الابتكارية والابداعية فى تفهم العلاقات المختلفة من الظواهر الكونية الموجودة التي تحبط به ، كما يكتب عادات الترتيب و التصنيف والتنسيق بين الموجودات في العناصر الطبيعية ثم يحاول الاستفادة منه ، فبالر غم من أنه من الصعب أن يتطابق عنصر ان من فصيلة واحدة إلا أنه قد تثابه فى هيئتها الخارجية

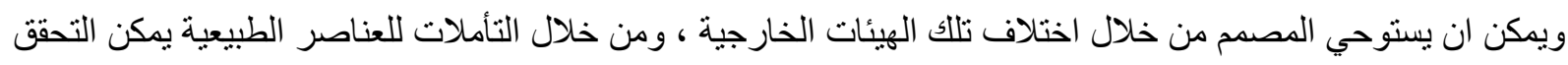
منها و اكتشاف ما بينها من علاقات مختلفة قد تساعده على أداء تصميمه بشكل مبتكر وجيد، فبقدر إدر الك ووعى المصمم لهذه العلاقات المتثابكة، و إمكانية الاستفادة منها و إعادة صياغتها باثكال مختلفة فإن ذلك يساعده فى إيجاد الحلول التصميمية المبتكرة .

فالتركيب الثعاعي داخل النبات له تركيب داخلى لنظام يتز ايد فية أوتوماتيكيا بدون توجيه أو تحكم من مصدر خارجى، فهو محور أساسى في الأنظمة البيولوجية التركيبية داخل الكائنات الحية بدأ من تركيب الخلايا الداخلية حتى أنظمة البيئة الخارجية و أنظمة التركيب الذاتى يخضع إلى خو اص تصاعدية عددية من كيان بسيط إلى مركب معقد بشكل كبير جدا ، و هذا المفهوم يرتبط بالبيوكيمياء وهو مختص بدراسة الجزيئات و الخلايا وتداخلها مع الكل لإنتاج أنظمة معقدة،

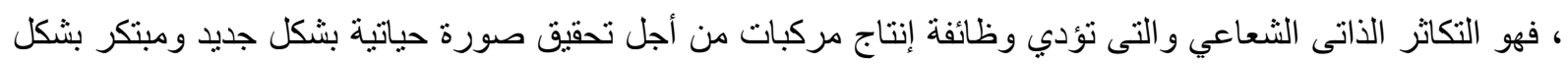

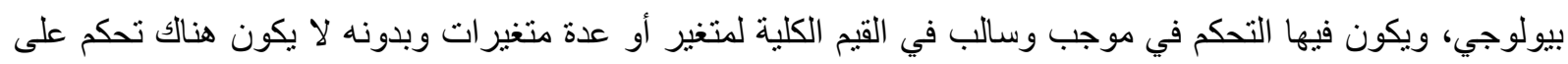
الإطلاق على النظام كله بشكل متكامل حيث ان النظام خاصية من خو اص الكون الذى يشمل العديد من العلاقات المعقدة و المتتو عة، ولقد تناولت العديد من الأبحاث فى علم الجمال علاقة الفن بالطبيعة الخارجية وتطرقت إلى الكثف عن قو انين الطبيعة"( 2)، وما تخلقه من علاقات وتر اكيب ونظم للأشكال تحقق القيم الجمالية، " وفى هذا المعنى يقول الناقد الفنى " كليف بل Clive Bell " إن أى بحث علمى لتظور تركيب الأجسام العضوية أو غير العضوية، يؤدى إلى إظهار كثير من الأشكال المتعددة و التر اكيب المتغيرة ذات الانساق المتكامل بشكل كبيرمن الوجهة الفنية و الجمالية، وينطبق هذا على الأشكال

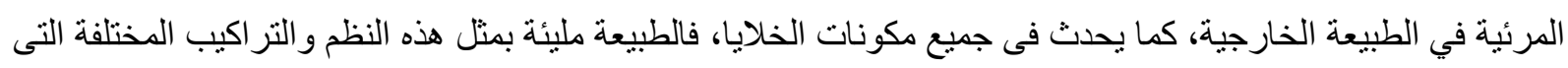
لها قو انين عامة تتحكم فى بئيتها وبالتوصل إلى تلاك القو انين يمكن التوصل إلى بناء الثكل فى الطبيعة وتطبيقاتها فى الأعمال 
فالقو انين الطبيعبة المتحكمة فى عمليات النموو النظم داخل وخارج الكائنات الحية في التكوين لا تختلف مهما تتوعت نسب النمو و الخامات الأساسية أن هذه القوى ثابتة لا تتغير بتغير الزمن ابدا، وهذا الإدر الك جعل كثيرًا من علماء الجمال يستتنجون

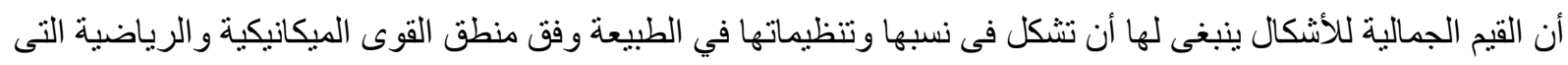

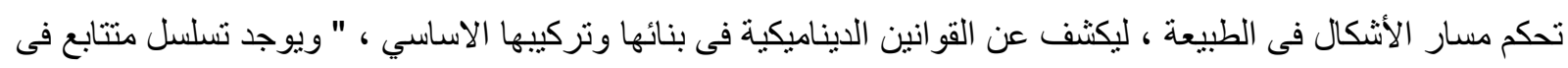
النظام البنائى فى نظم النمو للنظام الثعاعي في العناصر الطبيعية ويضح ذلك في النباتات ، كما يجب التعرف لأنس على الهيئة

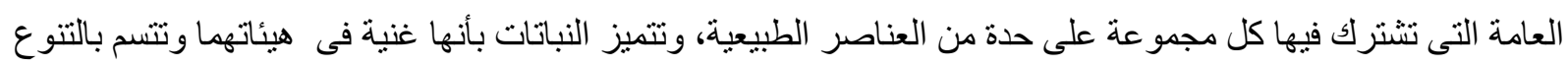
و الفر ادة ، تللك التى تنتج من تفاعل الحياة العضوية مع البيولوجية "(4)، إلى جانب تميز ها بالتنوع الثديد في الثكل و الهيئة بين كل نباتين من نفس الفصيلة الواحدة من النباتات ، فتتضح علاقة ذلك بالمظهر الخارجى فى الطبيعة ذو الثلاثة أبعاد

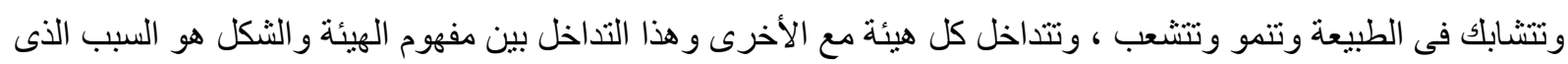

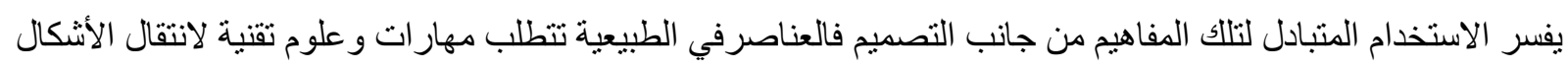
من الطبيعة الي التصميم بمهارة عالية والفن ودر اسة الطبيعة ليست الهدف، ولكن الهدف الوصول إلى تلك النظم و القو انين و التى تنتشر فى الكون وتكون أحيانًا واضحة وأحيانًا تختفى ور اء المظهر الخارجى ولا يتضح منها غير تللك الصيخ الجمالية

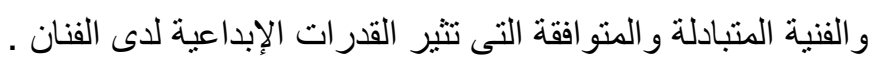

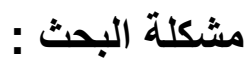
ما مدي امكانية اثر اء فكر المصمم باستحداث النظم الثكلية الثعاعية للكائنات في الطبيعة لتحقيق قيم ايجابية مما يوسع

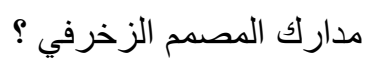
هدف البحث: ـ استخلاص الاسس التي صاغت من خلال النظام الثعاعي للكائنات في الطبيعة و الاهتمام بدر اسة البنية الخارجية للاشكال باستخدام الوسائل التكنولوجية الحديثة. ـالربط بين الطبيعة بالفن وذلك من خلال دراسة البنية الثكلية الخارجية للعناصر في الطبيعة أهمية البحث: تكمن أهمية البحث في استخلاص صياغات وتصميمات جديدة من خلال النظم الثعاعية في الطبيعة لابتكارتصميمات تثري مجال التصميم فروض البحث: يفترض البحث ما مدي الاستفادة من النظم البنائية الثكلية للشعاعيات في الطبيعة باستخدام التكنولوجيا الحديثة وبرامج الجر افيك مما يوسع مدارك المصمم الزخرفي. حدود البحث: تركز الحدود الموضوعية للبحث علي حدودًا زمنية تقتصر على دراسة الاسس البنائية للشعاعيات في الطبيعة لاستخلاص

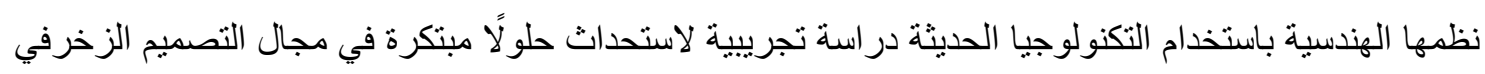

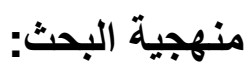
المنهج الوصفي التحليلي و التجريبي من خلال تنتع الاسس البنائية للشعاعيات في الطبيعة لابتكار تجارب فنية و تصميمية مستحدثة تثري مجال التصميم بشكل مبتكر. 
النظام البنائى : هي اعادة بناء النثكل، فالنظام البنائي هي محاولة لإيجاد الثوب الملائم للفكرة أو الانفعال بالثكل وهي عملية احكام العلاقات لهذه الفكرة مما ينطلب الحركة بالتصميم إلي انسب وضع ملائم. الثعاعيات: الثعاعيات في الطبيعة هي النظم الثكلية وتتحدد طبيعتها المرئية بتنسيق الخطوط والتحكم في حركاتها و إتجاهاتها الثكلية الخارجية ولهذا فإن الخطوط هي التي تقوم بتشكيل الهيكل البنائي ، حيث أن خطوط الثنكل لينة تتجه إلى العق بشكل إنعاعي من المركز وفهو عبارة عن شكل كروى محاط بنتوءات وشعيرات فى كل الجوانب، مما ينتج تصميمات متتو عة من الخطوط الاشعاعية ، فالخط يعتبر وسيلة أولية و أساسية للاتصال البصري بوصفه ونس أساسًا للتعبير في

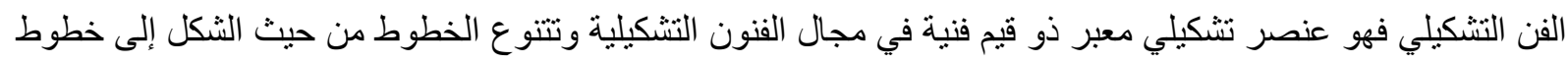
هندسية وخطوط حرة وتنتج الخطوط الهندسية باستخدام أدوات الهندسة أو الخطوط الحرة ، " فهي غير منتظمة وتتسم بالتلقائية ومن خلال النظم البنائية الثكلية حيث أن الخطوط و الحركة فيه تكون في اتجاهات مشعة من المركز كما أن الثكل له طبيعة حيوية متنوعة، فالخط له قيمته الثكلية ودلالاته، فالنظم الخطية فيه تنتوع بين الخطوط المستقيمة المتنوعة و الإتجاهات اللوليية، الحرة و الإشعاعية" (7).

مجال التصميم الزخرفي: التصميم الزخرفي هو ا احد انواع التصميم التي تستخدم الصياغات التصميمية الزخرفية في

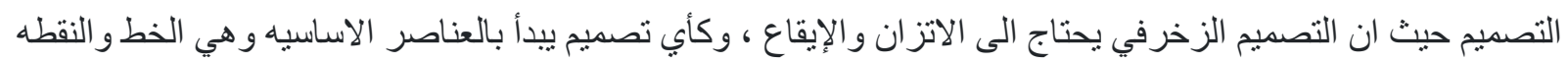
و اللون ويحتاج الى الإبداع في الفن و الابتكار وهو ا فن قائم على مفهوم التكوين و الصباغة بشكل كبير والتي تمثل بدور ها تجمع العناصر الاساسيه و الأشكال الهندسية لتعطي شكلا يحتوي علي الابتكار في العمل الفني.

\section{اولا : نبذة عن الشعاعيات في الطبيعة :}

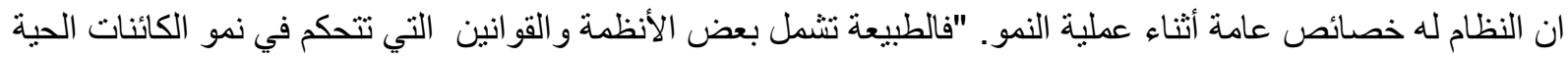
وجميع أنواع النباتات "ومن أهم ما كثفت المعرفة الحديثة حول الطبيعة أن بناء كل موجداتها قائم على قو انين جوهرية

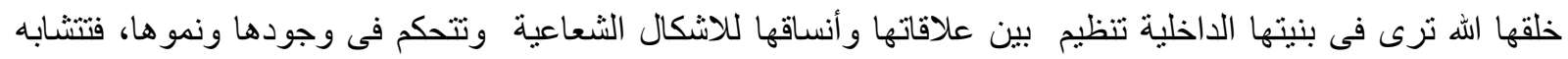
أسسها البنائية مما أدى إلى ظهور مفهوم جديد للطبيعة أطلق عليه مبدأ ( وحدة الطبيعة )، وهذا المبدأ الذى تنمو بمقتضاه سائر الكائنات في كل الكون حية كانت أو جامدة، ذرات أو خلايا، "(9) وبهذا المبدأ أصبح مفهوم الطبيعة هو يعنى القوة الوحدة المسيطرة على هذا النظم والنسق للاشكال الثعاعية في الكون و الوجود فى إطر اده المتشعب ونموه وتطوره ،

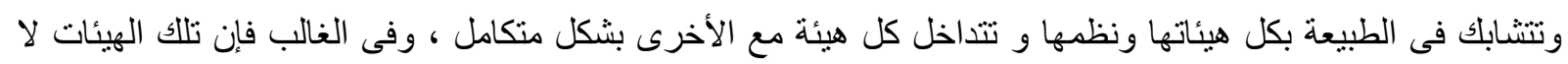

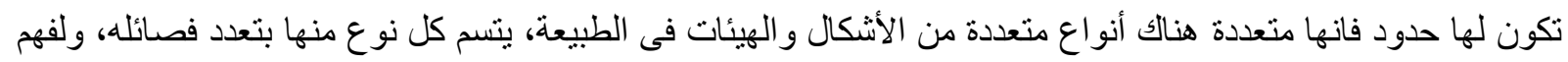
الهيئات والأشكال فى الطبيعة ، بمكن تصنيف الهيئات فى الطبيعة فى سلسلة من المجموعات المتشابهة، لتيسير دراستها ولقد اهتمت كثثر من البحوث الفنية المعاصرة بالبحث عن قوانين النمو فى الطبيعة التى تقوم على العديد من المجالات المتضنة للنظم التركيية و الثنلية فى عالم النبات والحيوانات و الطيور وغير ها والتى يقبل عليها الفنان وتكون له بمثابة المصدر و المنبع الذى يستلهم منه إبداعه الفنى، فمن خلال تناوله بفهم واعى و إدر الك عميق لكيفيات بنائها بمكو ناتها اللانهائية تصبح من المصادر الفعالة لأنماط متعددة من الخطوط و الأشكال و العلاقات التشكيلية. 

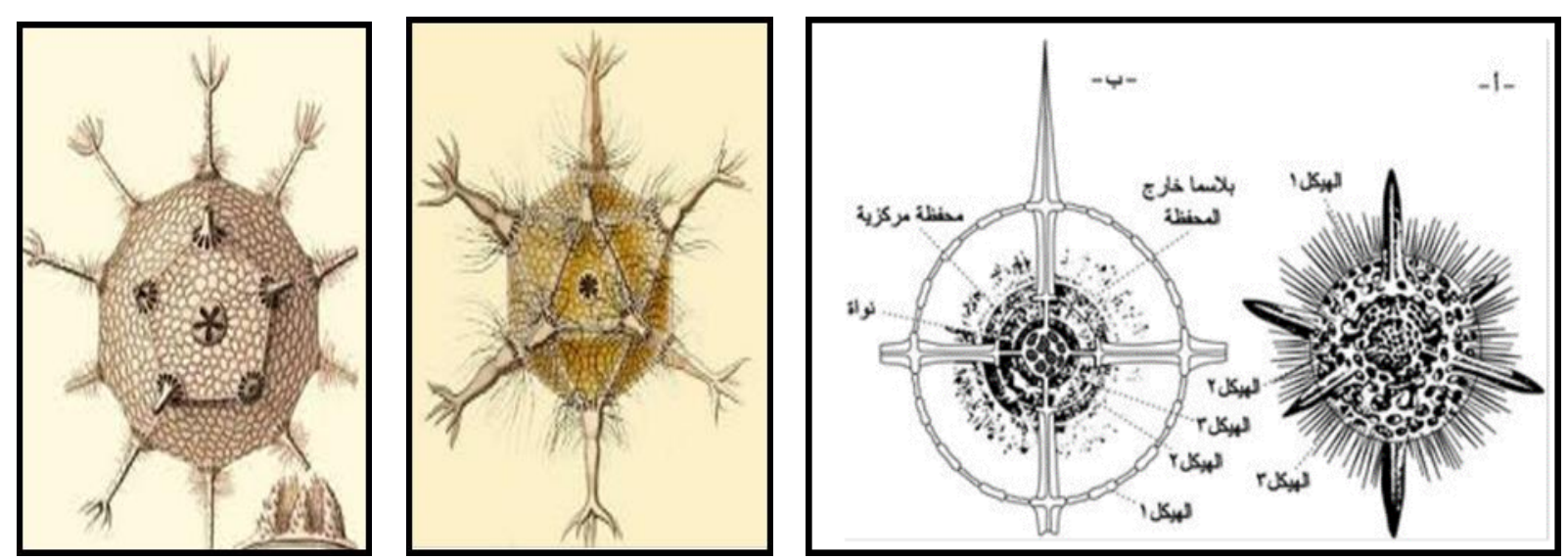

شكل رقم (1) حيو انات بحرية شعاعيات الأرجل من البحريات الأوالي معظمها كروي الثكل وذات أرجل كاذبة من النمط الثعاعي
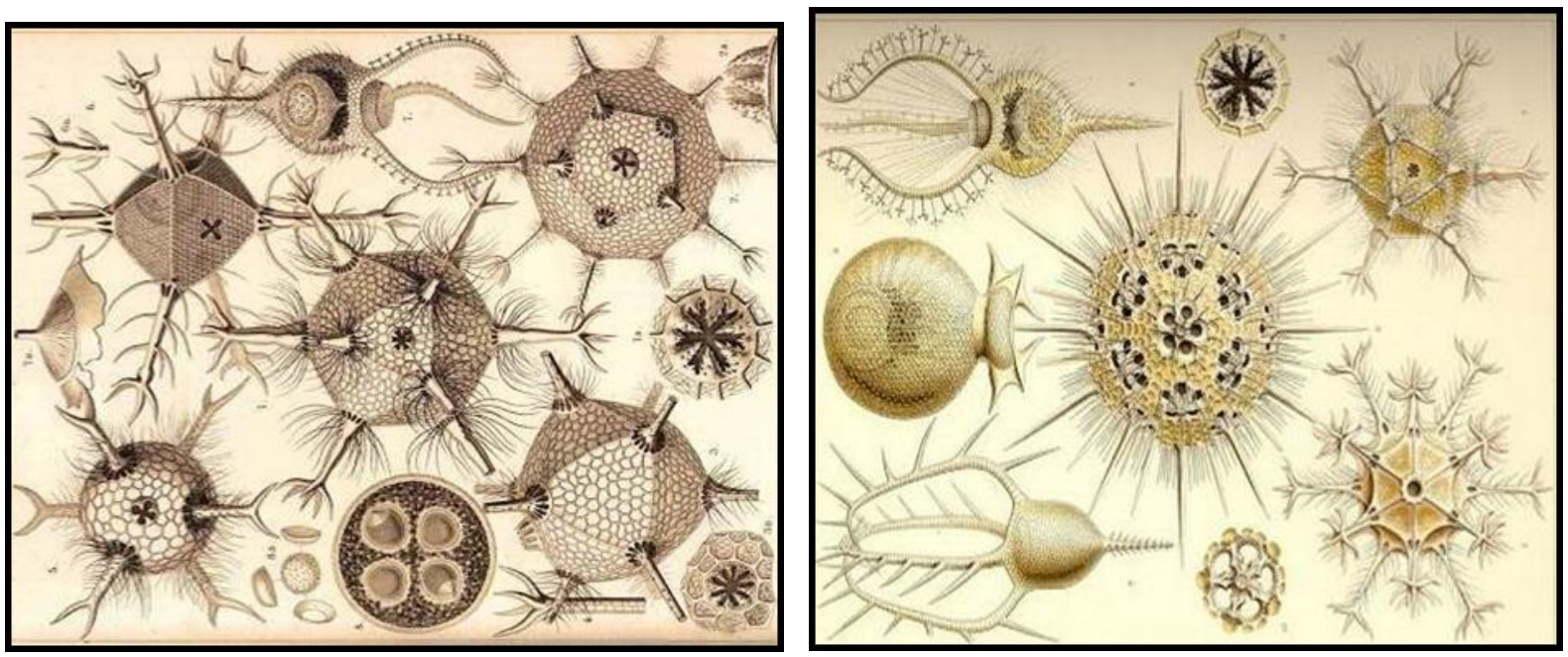

شكل رقم (2) حيو انات بحرية تحتوي علي محيط بالسيتوبلازما الخارجية، مؤلف من أشوالك متفرعة تحيط بالجسم البحري ، وتُفْنَّ بترسبات سيليسية، أو تتجمع عليه الأشواك التثكل شعاعيات بقشرة رقيقة، شبكية كروية
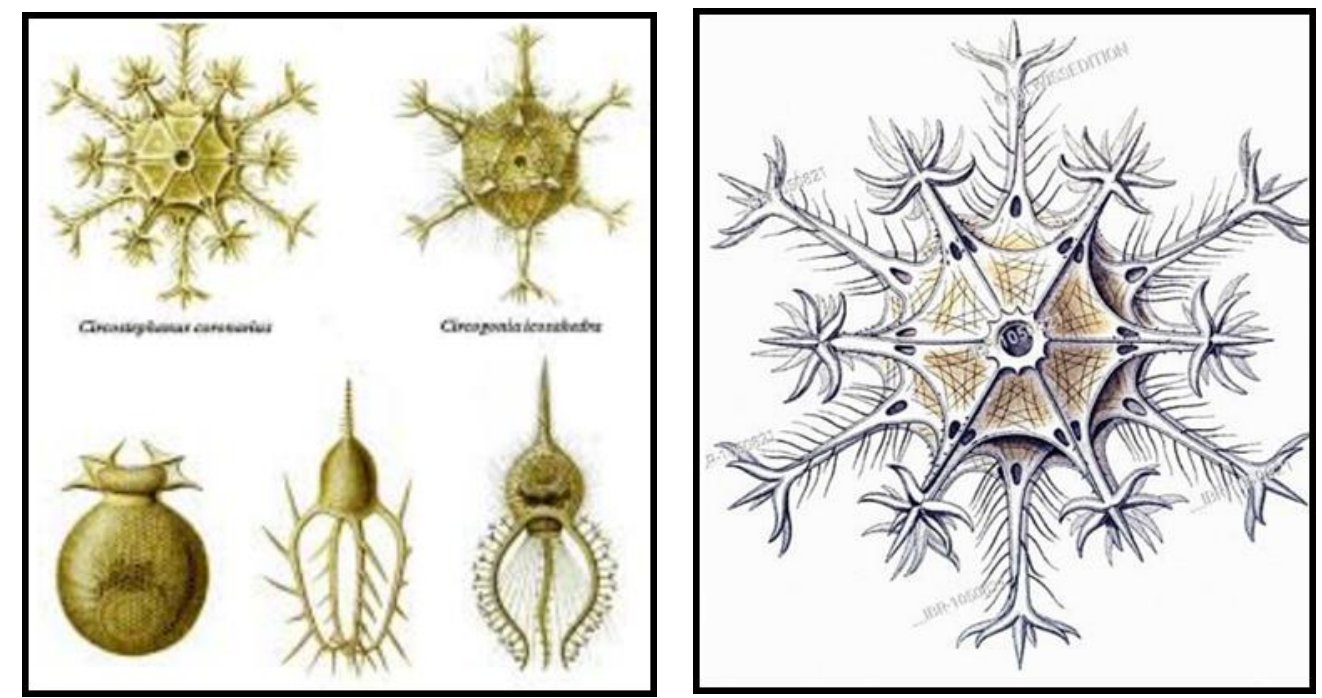

شكل رقم (3) حيوانات تعيش في البحار والمياة العذبة مثل الهيدرا ةالاوبليا والجوفمعويات والطلانعيات 


\section{ثانيا: سمات التصميم والهيئات الشعاعية في الطبيعية:}

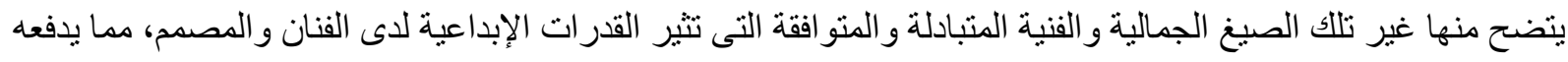
إلى البحث عن هذه الصيغ بالدر اسة والتحليل و التصنيف والتجريب وذللك للتعرف على الاسس البنائية للتصميم من خلال مستويات الإبداع الفني فى صياغة هذه النظم ثم محاولة إعادة صياغتها مرة اخري بشكل يرضى إبداعه الفنى و الجمالي "

$$
\text { (1) واهم سمات الهيئات في الطبيعة: }
$$

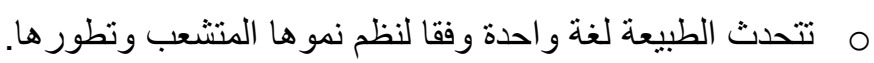

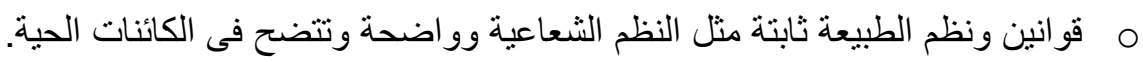
م تتبع الهيئات الأساسية الاولية فى الطبيعة بأبسط الطرق و اسهلها، وتتسم فصائلها بالتتوع و التفرد الكبير. م تعمل الطبيعة وفقا لقو انين هندسية ورياضية تتقارب فيما بينها وتتسم بالمرونة والابتكار. O فى الطبيعة نظام كالنظم الثعاعية كبيروو اسع يتحكم في تكوينها، يعكسه المصمم فى عمله الفني. م يكتشف المصمم نظم الهيئات في الطبيعة الثكل و الجوهر من خلال قو انين عمله. O هناك علاقات وثثقة وقوية يعبر بها المصدم في عملة الفني عن النماذج العضوية و الغير عضوية للنظام الثعاعي مهي O م ينقل المصمم الهيئة و النسبة من الطبيعة من خلال عقله اللاو اعى بطريقة حدسية إلى عمله الإبداعى. م تكمن داخل الهيئات الطبيعية لغة واحدة ونظم داخلية مثل النظم الثعاعية وخارجية يتكثفها المصمم ويتضح أن در اسة الطبيعة ذاتها مرجع أساسي ومصدر استلهام للفنان حيث بستوحي العناصر و الأسس التى تعتمد فى بناياتها

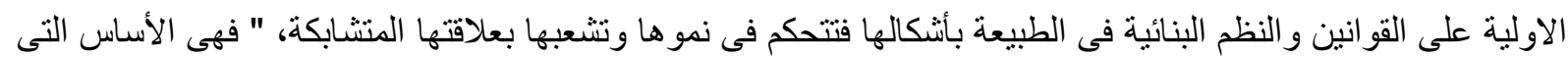
يشتق المصمم عناصره ومفرداته والنظم البنائية للعناصر في الطبيعة ، فقد كان للعلماء مكانة كبيرة فى تحليل العلاقات

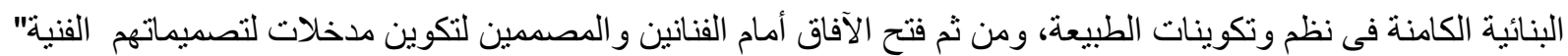

\section{ثالثا : النظام الرياضي الثعاعي للتباتات فى الطبيعة :}

تتعدد الأصناف للنباتات في الطبيعة لان الاشكال يمكن ان يستوحي منة عدد لانهائي من التصميمات المختلفة ، لذلك يناتئى

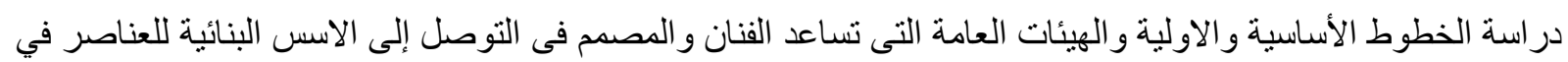

الطبيعة "(6) (2)
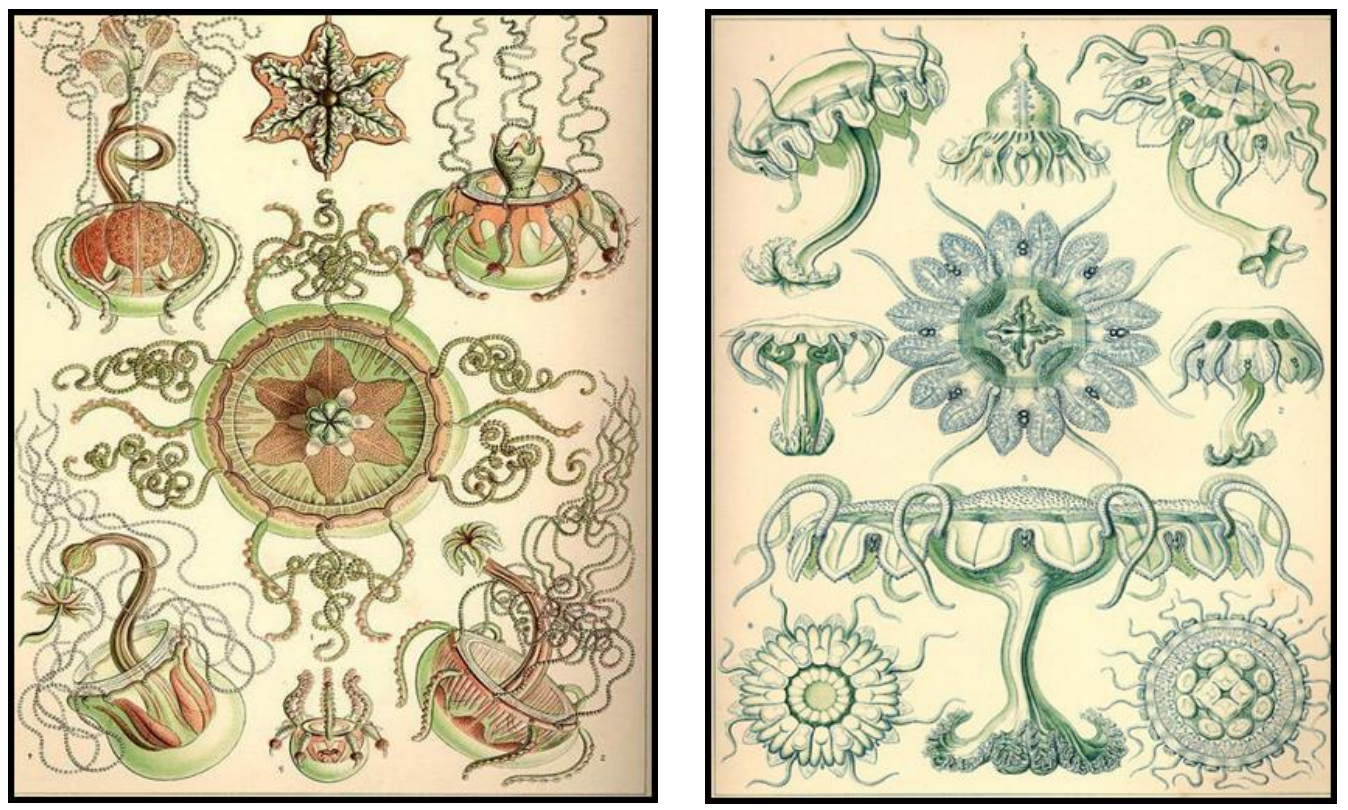

شكل رقم (4) طائفة من المحاريات والقواقع البحرية بثكل تصميمي من خلال برامج الجرافيك 


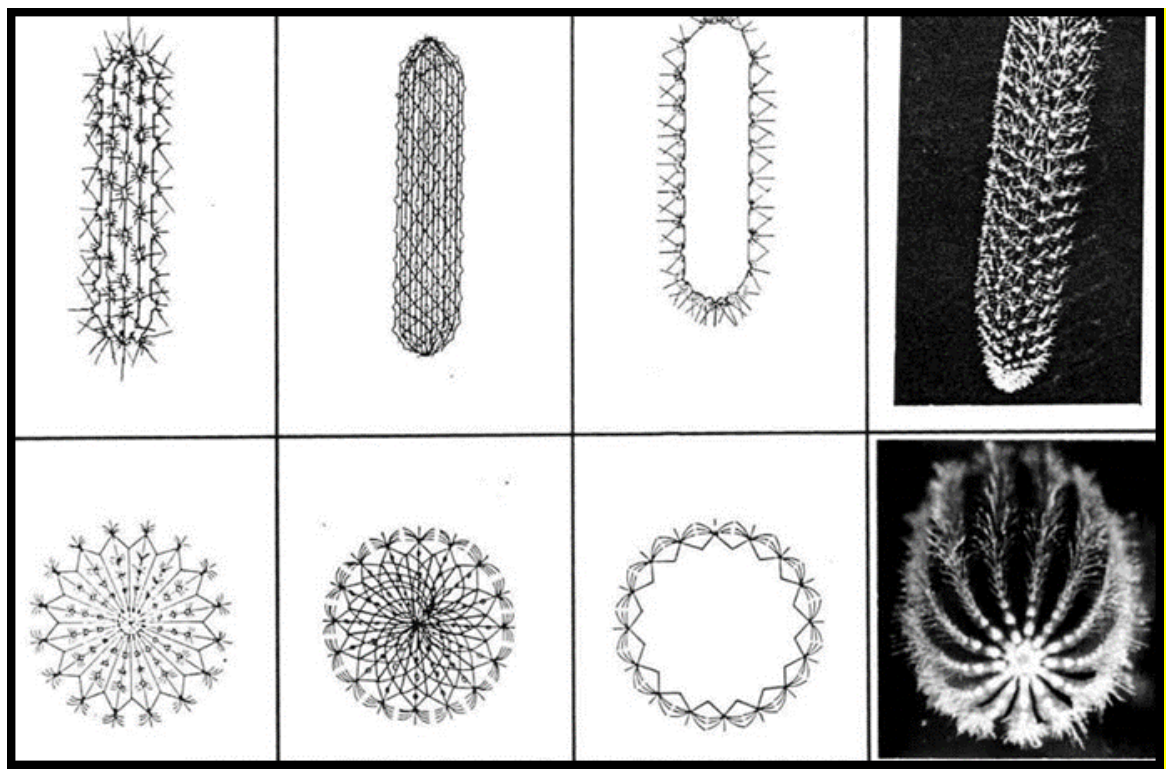

شكل رقم (5) يتضح من خلالة نبات الصبار بشكل متشعب شعاعي في النظام البنائي للنبات

ان معظم نظم الخطوطو الصياغات التصميمية و الهيئات و التى تتناسب مع هيئة المجال المغناطيسى للجاذبية الارضية، الذى يعطى القوة و الحركة للنبات" ، و النباتات التى لا يتبع نظام نموها هذا المجال، يتبع نظام نمو ها الخط الحلزونى الذي يعطي

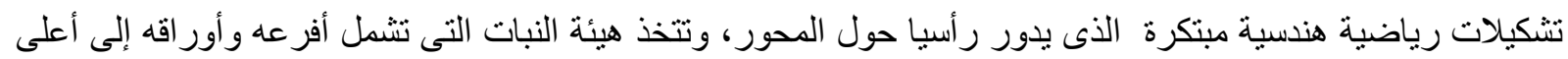
وجذوره إلى أسفل بشكل متشعب شعاعي في النظام البنائي للنبات"(8).
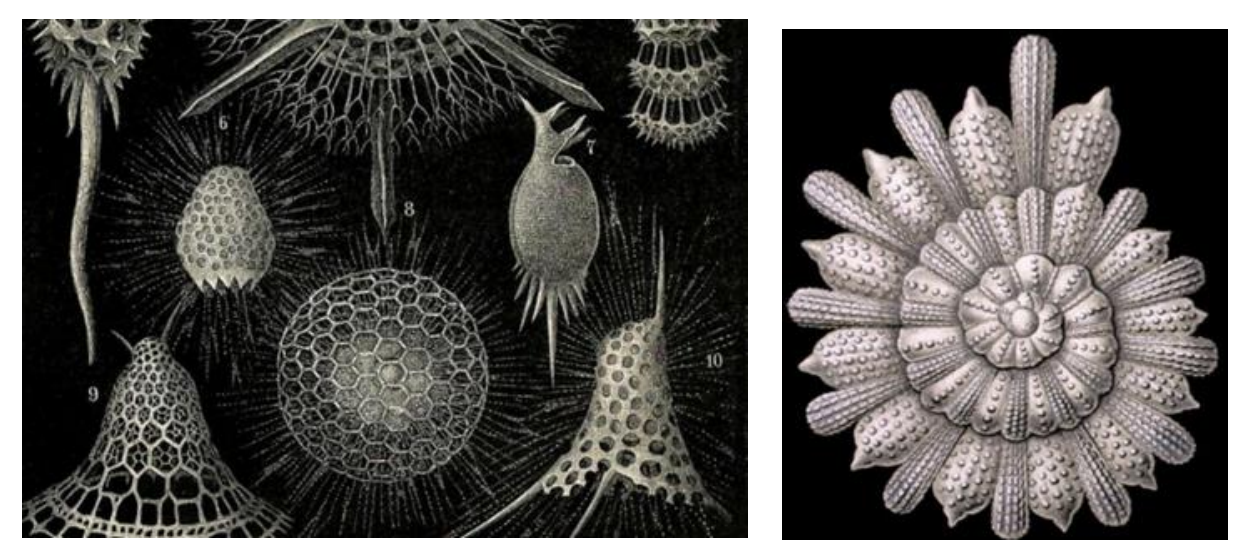

شكل رقم (6) هياكل بحرية هيكلها سيليسي، مؤلف من قسمين، قسم محيط بالسيتوبلازما الاخلية التي تحوي النواة الاساسية ، يسمى

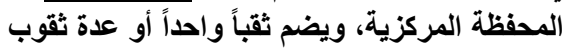

وتعد أكثر الشعاعيات شيوعا في البحار، وتصادف في أعماق المختلفة، هيكلها سيليسي، مؤلف من قسمين، قسم محيط بالسيتو بلازما الداخلية التي تحوي النواة الاساسية ، وجزء يسمى المحفظة المركزية، ويضم ثقباً واحداً إن تتوع هذه

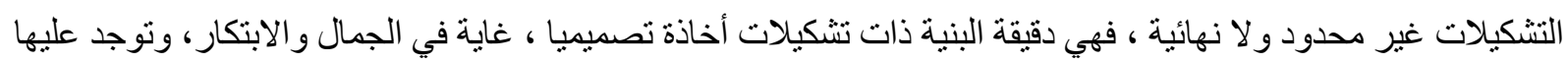
ثقوب مرتبة ومتناسقة بثكل هندسي رياضي منتظم مميز لكل نوع، تخرج منها الأرجل الكاذبة بشكل خيوط دقيقة حول الحيو اني البحري، تساعد في التقاط الفرائس الممثلة بالعو الق الدقيقة وتعيش الثعاعيات في البحار فقط في المياة المالحة ، ويمتد انتشارها حتى عمق 5000م تقريباً تحت سطح البحر، وقد تكيفت مع الحياة العالقة البحرية ، بسبب التشكيلات

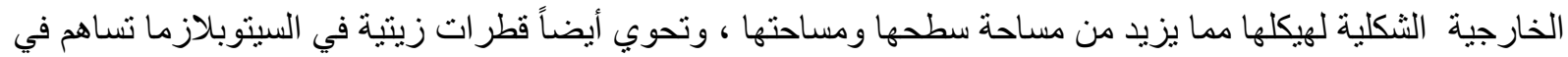
تخفيض وزنها النوعي، ومساعدنها في العوم علي السطح والطفو عل سطح الماء، تتكاثر الثعاعيات بالانشطار الثنائي، في 
حين لم تعرف بعد مر احل تكاثر ها بدقة شديدة ،ويتضح ذلك في الحيوانات البحرية الزهرية الملونة التي لها قرص فمي

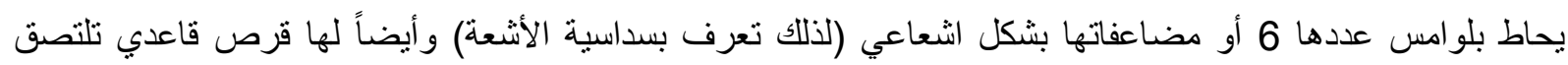

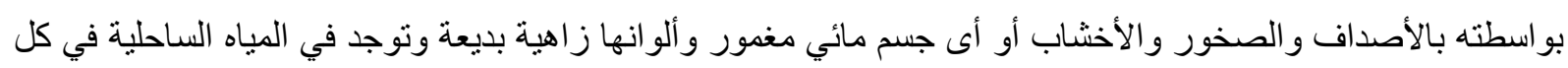

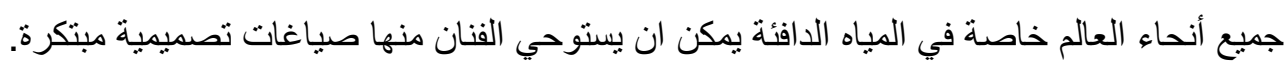
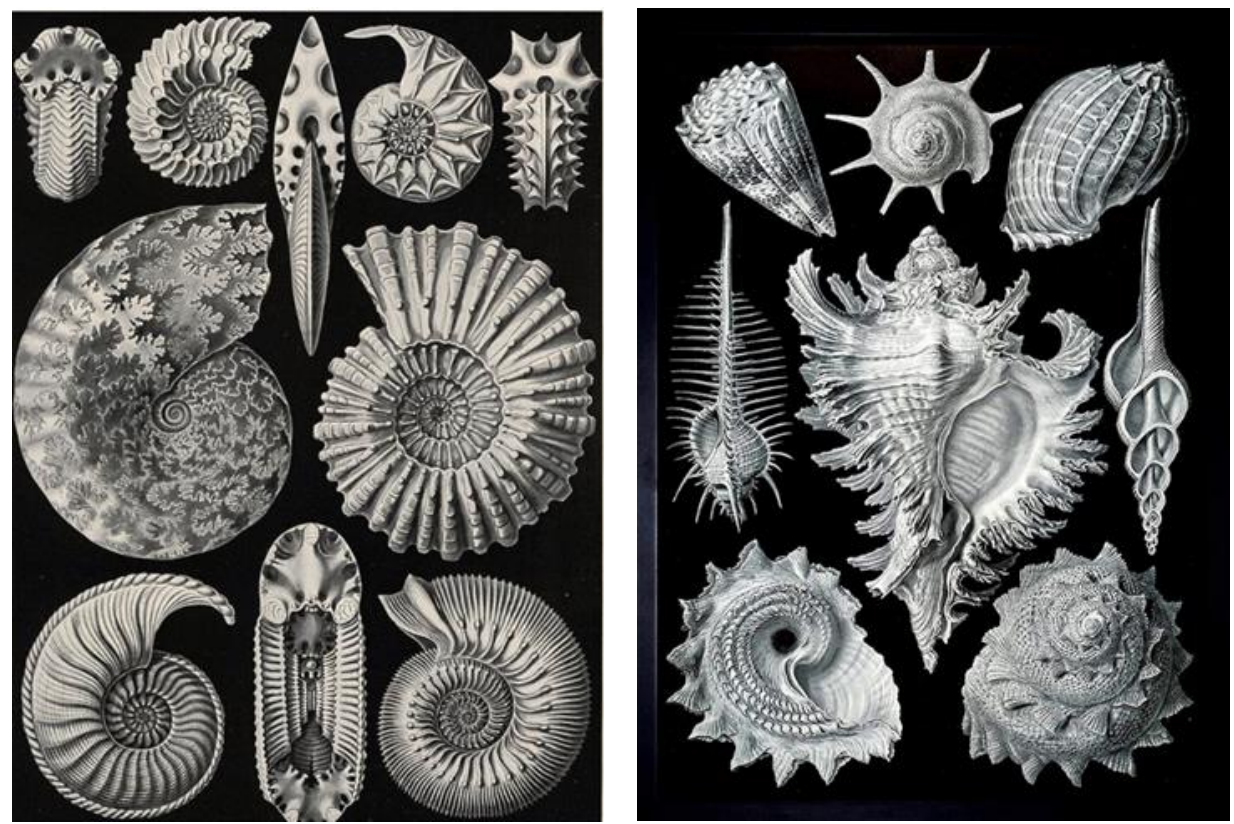

شكل رقم (7) طائفة من الححاريات والقواقع البحرية بثكل تصميمي من خلال برامج الجرافيك

خامسا: النظام الخطي الشكلي للشعاعيات في الطبيعة: الثعاعيات في الطبيعة هي النظم الثكلية و الحركية للعناصر في الطبيعة وتتحدد طبيعتها المرئية بتنسيق الخطوط و الاشكال و التحكم في حركاتها الشعاعية وإتجاهاتها الثكلية الخارجية ولهذا فإن الخطوط الثعاعية هي التي تقوم بنتكيل الهيكل البنائي ، حيث أن خطوط الثكل لينة تتجه إلى العمق بشكل إثعاعي من المركز مما توحي بالعمث وفهو عبارة عن شكل واتهل كروى محاط بنتو عات وشعير ات الثعاعية فى كل الجوانب، مما ينتج تصميمات متنوعة من الخطوط الاشعاعية ،" فالخط يعتبر وسيلة أولية وأساسية للاتصال البصري المرئي بوصفه أساسًا للتعبير الفني في الفن التشكيلي فهو عنصر فئس تنكيلي معبر ذو قيم فنية في مجال الفنون التشكيلية وتتنوع الخطوط من حيث الثنكل إلى خطوط هندسية ومستقيمة ومتعرجة وخطوط حرة وتنتج الخطوط الهندسية باستخدام أدوات الهندسة الرياضية أو الخطوط الحرة ، فهي غير منتظمة ومتعرجة وتتسم بالتلقائية ومن خلال النظم البنائية الثكلية حيث أن الخطوط والحركة فيها تكون في اتجاهات مشعة من المركز الي الداخل كما أن الثكل له طبيعة حيوية متنو عة ومتغايرة ، فالخط له قيمته الثكلية ودلالاته، مما يوحي بالعمق و والالابعاد ، فالنظم الخطية فيه تتتوع بين الخطوط المستقيمة و المنحنية والمتنوعة و الإتجاهات اللولبية المنحنية ، الحرة والإشعاعية" 

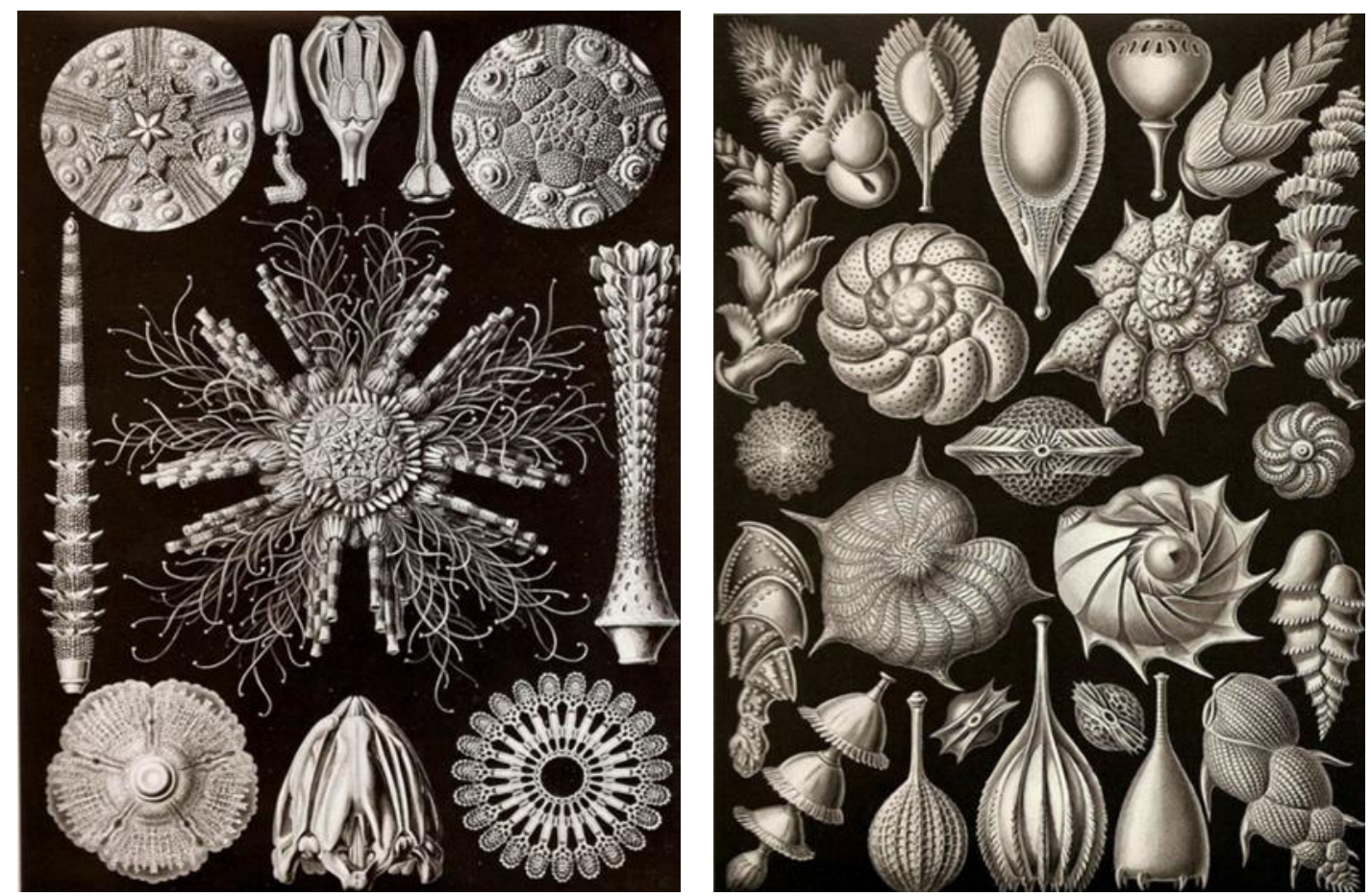

شكل رقم (8) حيو انات بحرية شعاعيات الأرجل من البحريات الأوالي معظمها كروي الثكل وذات أرجل كاذبة من النمط الثعاعى طائفة الاوريليا والثعب المرجاتية
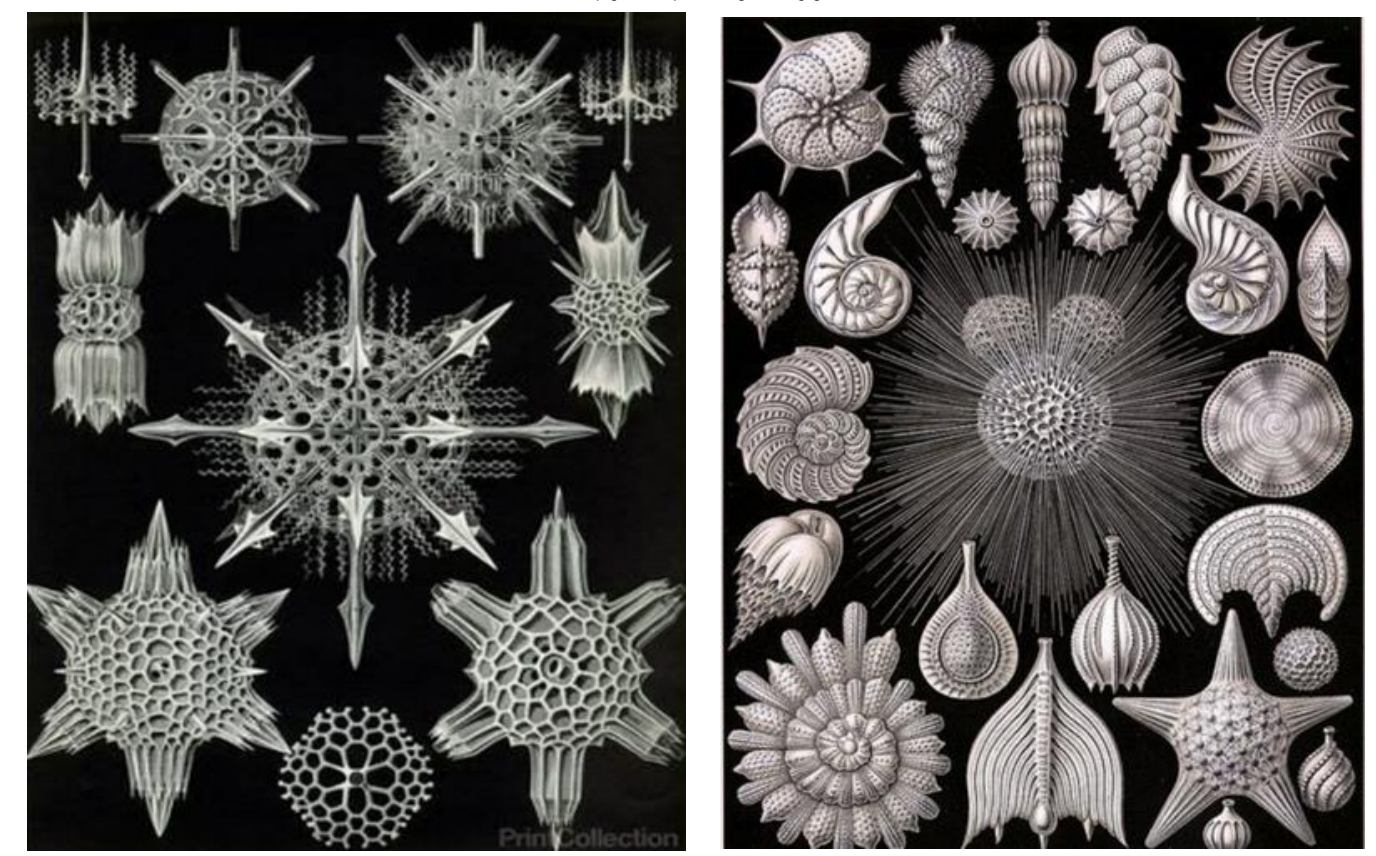

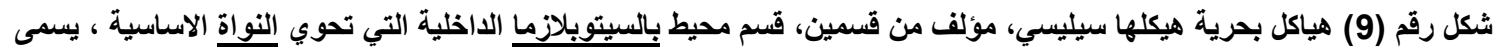

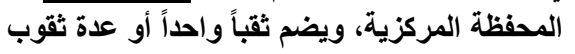

سادسا : الصياغة التصميمية الشكليه للشعاعيات والافادة منها في التصميم الزخرفي:

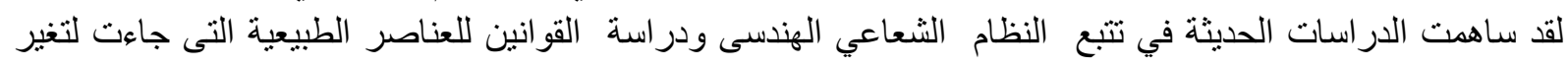
مفاهيم الإدراك القديمة من خلال تحليل للعناصر وذلك عن طريق اختراع وسائل وأجهزة الرؤية البصرية كالعدسات و المجهر الإليكترونى والتصوير الفوتوغر افى لأدق مكونات الطبيعة الخارجية حنى يسهل دراستها والتعرف على بنائها، الإمكانات جعلت التعامل مع العناصر الطبيعية أكثر ثراء، مما أتاح المجال لرؤية جديدة للفنان ، فالطبيعة المرئية بهيئاتها

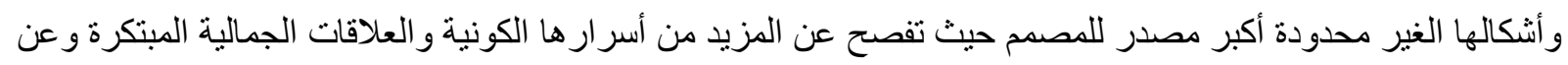


نظم وقو انين تكون بمثابة إثارة للمصممين و الفنانين و عناصر هم ومفرداتهم التشكيلية واللونية حيث يستوحى عناصر و أسس التصميم من خلال المفردات الموجودة فى الطبيعة الخارجية و الطريقة التى بنيت بها العديد من الهيئات المتتوعة و المختلفة ، فالمصمم يجرب ويتعامل مع متغيرات مختلفة ومتنوعة من أسس التصميم، فقد يثبت المصمم و الفنان عددًا من تلكي المتغير ات ويجرب بمتغير واحد أو أكثر حيث يؤدى جهده التجريبى و الفني على حركاتها فى مصفوفات شعاعية وتنظيمات مختلفة تتز ايد فى بعض أجزاء العمل الفنى وتتناقص فى البعض الآخر في التصميم .

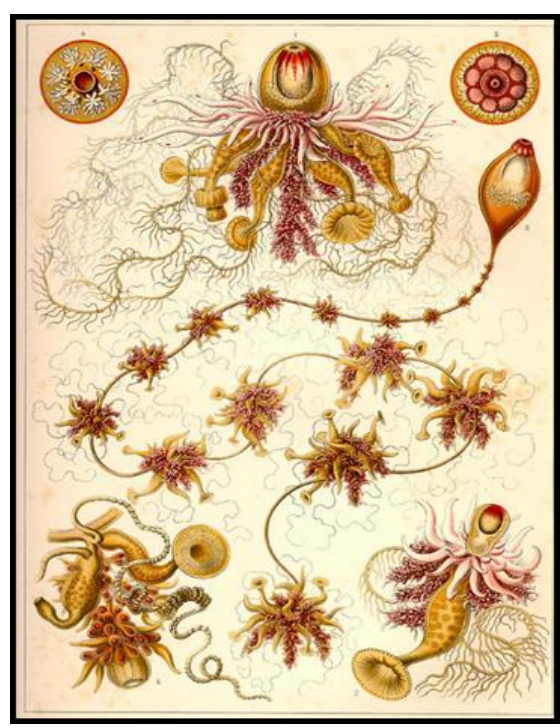

شكل رقم (10) حيوانات بحرية تحتوي هياكل بحرية هيكلها سيليسي، مؤلف من قسمين، قسم محيط بالسيتوبلازما الاخلية التي تحوي النواة الأساسية مؤف

\section{سابعا : النظم البنائية الثكلية بالهيئات الثعاعية في التصميم :} 1- التشابه بين الاجزاء في الثعاعيات:

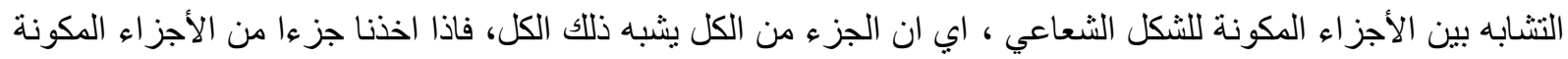

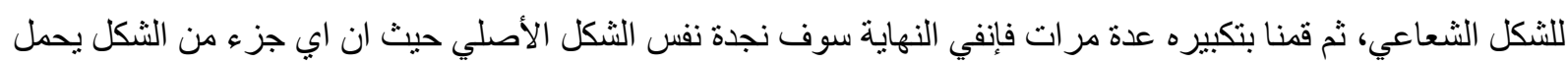
نفس صفات الشكل الاصلي حتى نصل الى الاقتناع بوجود خاصية التشابه الذاتي للشكل.
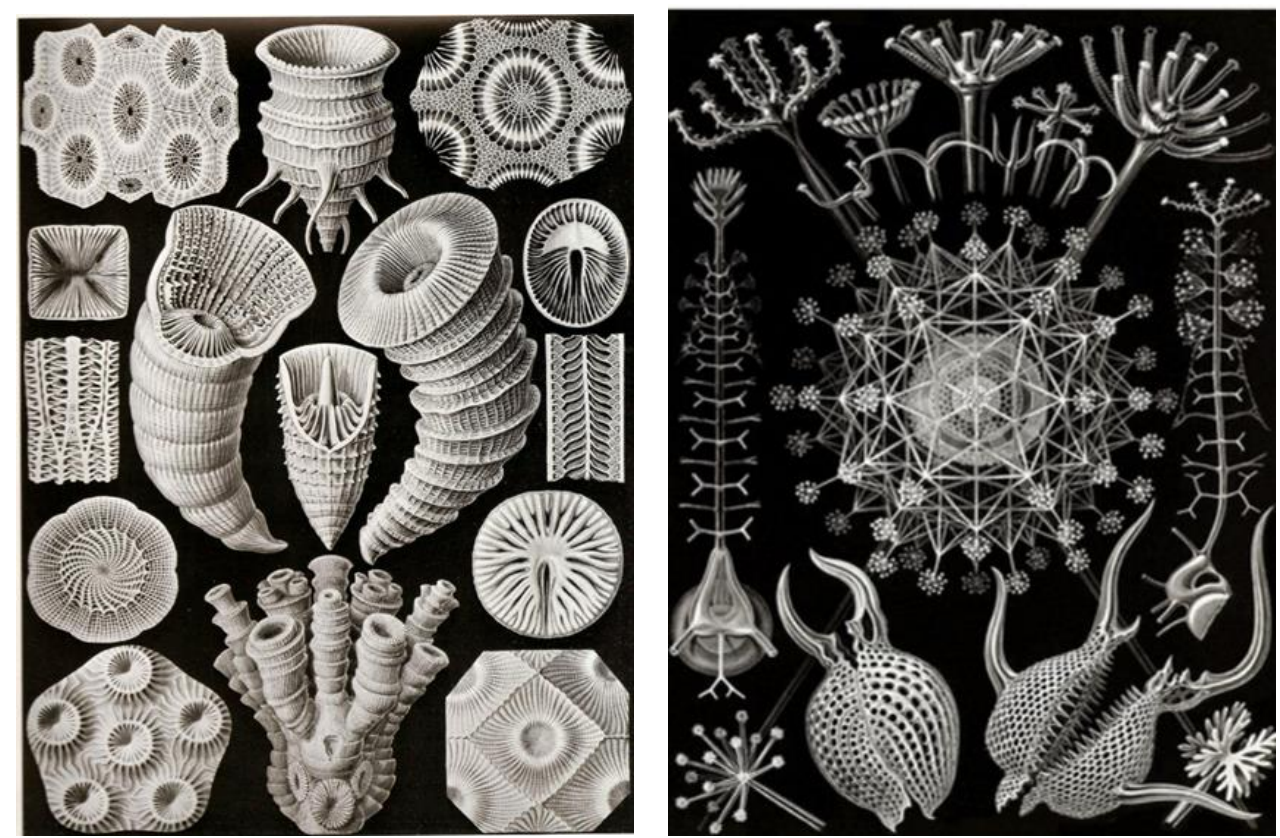

شكل رقم (11) حيوانات بحرية طائفة الفنجانيات بشكل تصميمي من خلال برامج الجرافيك 

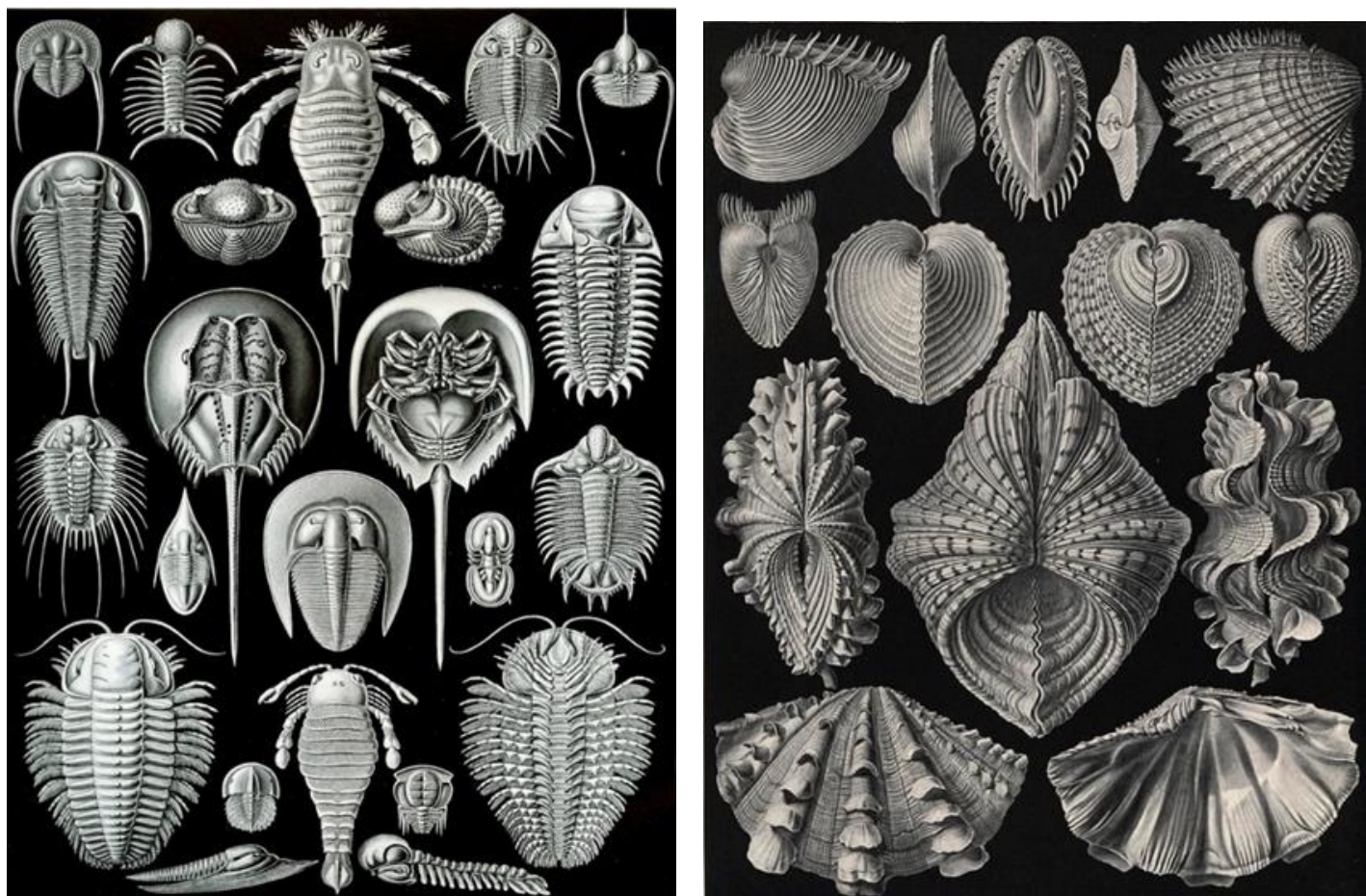

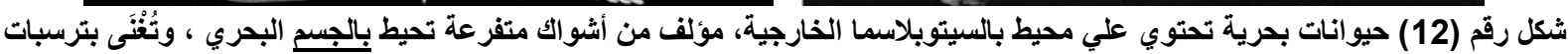

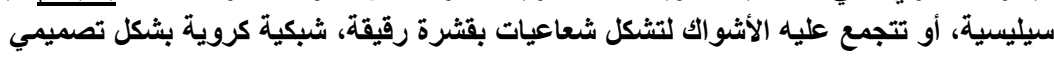

1- التكرار إستراتيجية أساسية للشعاعيات في الطبيعة : ويتضح أيضا فى دراسة التكوين و البناء الذاتى للثعاعيات أن المستويات التصاعدية للترتيبات الثئعاعية يؤكد أن هناك عمليات تكر ارية داخل كل فرد ويؤكد على التصميم القوى للأنظمة داخل الكائنات الحية لا تنتج بالتحسين والتوحد و إنما تتنج بالتكر ار و التثريق و التشعب.

2- - النظام الرقمى الرياضى للنباتات فى الطبيعة: بدأت در اسات متكاملة للنباتات و الكائنات الحية في الطبيعة بحثًا عن أنظمة خفية كامنة، ولقد أوضحت هذه الدر اسات أنظمة جديدة ومبتكرة ينتج منها أنظمة بنائية بشكل رقمى هندسي رياضى تساعد فى فهم الأداء التكوينى للنباتات وتركيب نماذج رقمية مناسبة يسمح لفهم السلوك الصاعد والمكونات التصاعدية والاستراتيجيات التأملية للأداء البيولوجى ويساعد هذا لاستكشاف الأداء الميكانيكى للنمو الثعاعي تحت ضغوط البيئة التلامسية ، ويتضح ذلك فى نبات البامبو و السرخس و النخيل

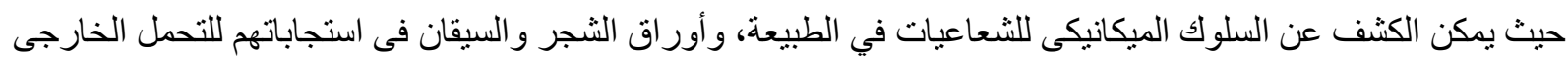
بأسلوب تصاعدى شعاعي لا حصر لها، وتوصلت الاتجاهات الحديثة فى مجال التصميم الزخرفي ويتضح انواع النظام

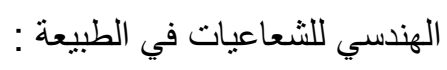

ـأثكال هندسية غير منتظمة تتكون من اجز اعمنشعبة غير منتهية للشعاعيات ومتداخلة بمختلف القياسات. -ان الصور التي تنتج من تكرار الثعاعيات من المعادلات اللا خطية والخطية المستقيمة و المتعرجة و المنحنية . ـأثكال هندسية نتجت أو نمت نتيجة تطبيق بعض القو اعد الهندسية والرياضية التي تأخذ الثكل الأساسي وتنقله من خطوة

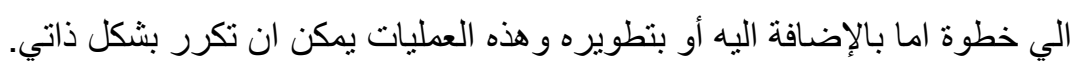
ـأنكال هندسية تنتج من تقسيم الثنكل الأساسي الي أجزاء صغيرة وكل جزء هوه هوه صورة مصغرة من الثكل الأساسي اي كل جزء صورة طبق الاصل من الثكل الاصلي. 

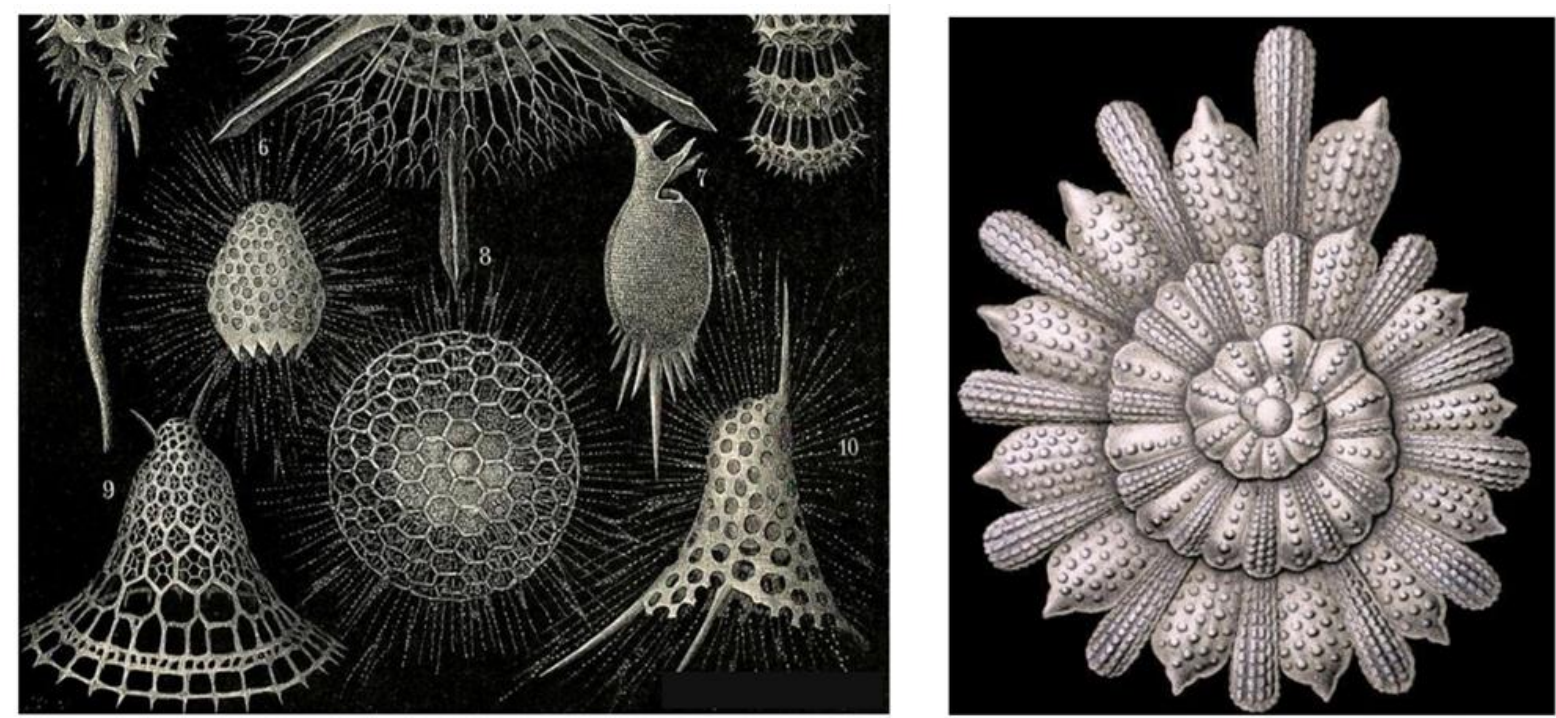

شكل رقم (13) حيو انات بحرية شعاعيات الأرجل من البحريات الأوالي معظمها كروي الثكل وذات أرجل كاذبة من النمط الثعاعي طائفة

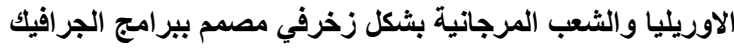

\section{ـ الدراسة التجريبية (العملية) بواسطة برامج الجرافيك:}

ـ تعد تجربة عملية مرتبطة النظام البنائي لهيئة الثعاعيات في الطبيعة لاستخلاص التراسية المفردات والنظام البنائي والافادة منها في التصميم الزخرفي وفقا لما يلية ـ استخلاص صياغات تصميمية من خلال تحليل النظم البنائية لتصميمات قائمة على النظام البنائي لهيئة الثعاعيات في الطبيعة لاستخلاص المفردات والنظام البنائي والافادة منها في التصميم الزخرفي وذللك من خلال استخلاص صياغات وتصميمات جديدة بالكمبيوتر لابتكار حلول لتصميمات جديدة وفق قوانين النظام البنائي لهيئة الثعاعيات في الطبيعة. ـ استخلاص صياغات تصميمية من خلال تحليل النظام البنائي لهيئة الثعاعيات في الطبيعة
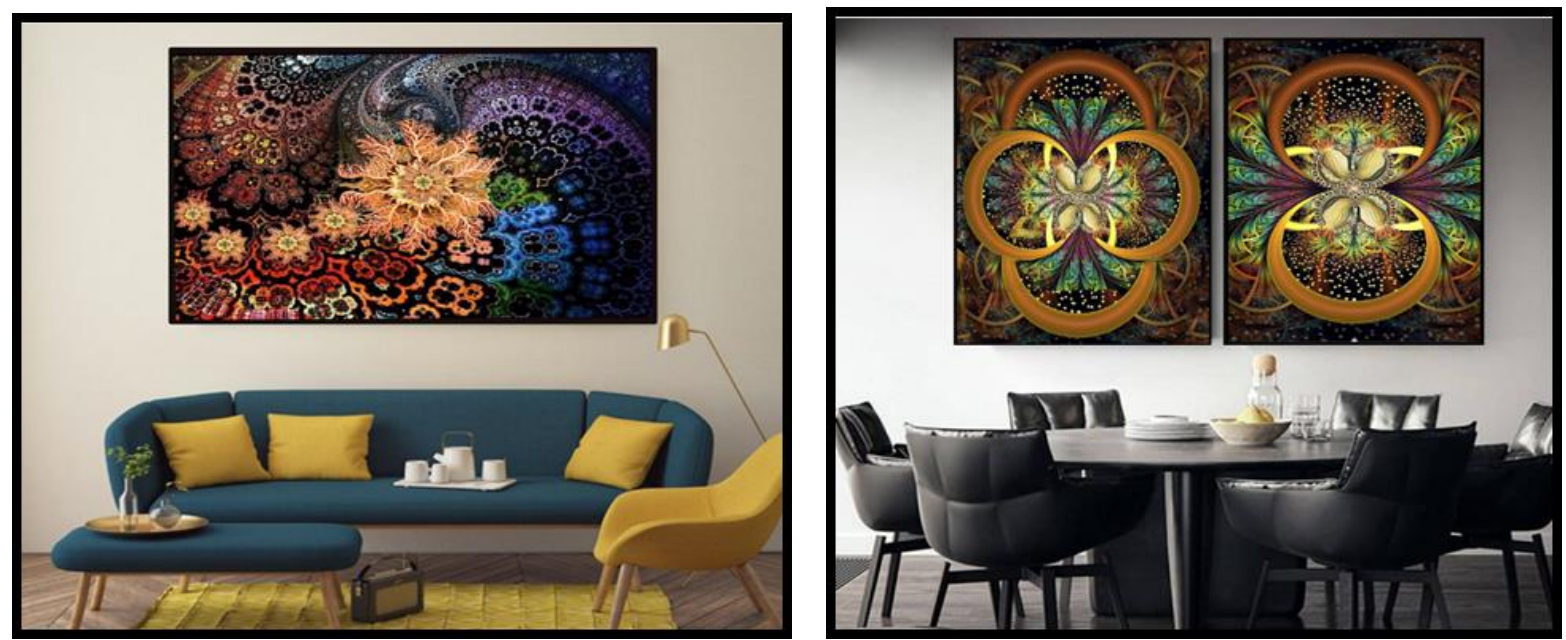

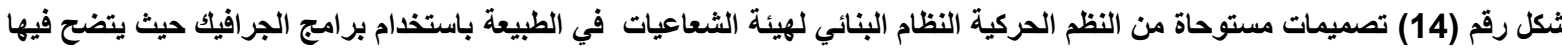

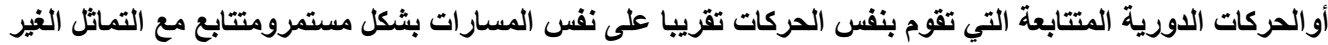



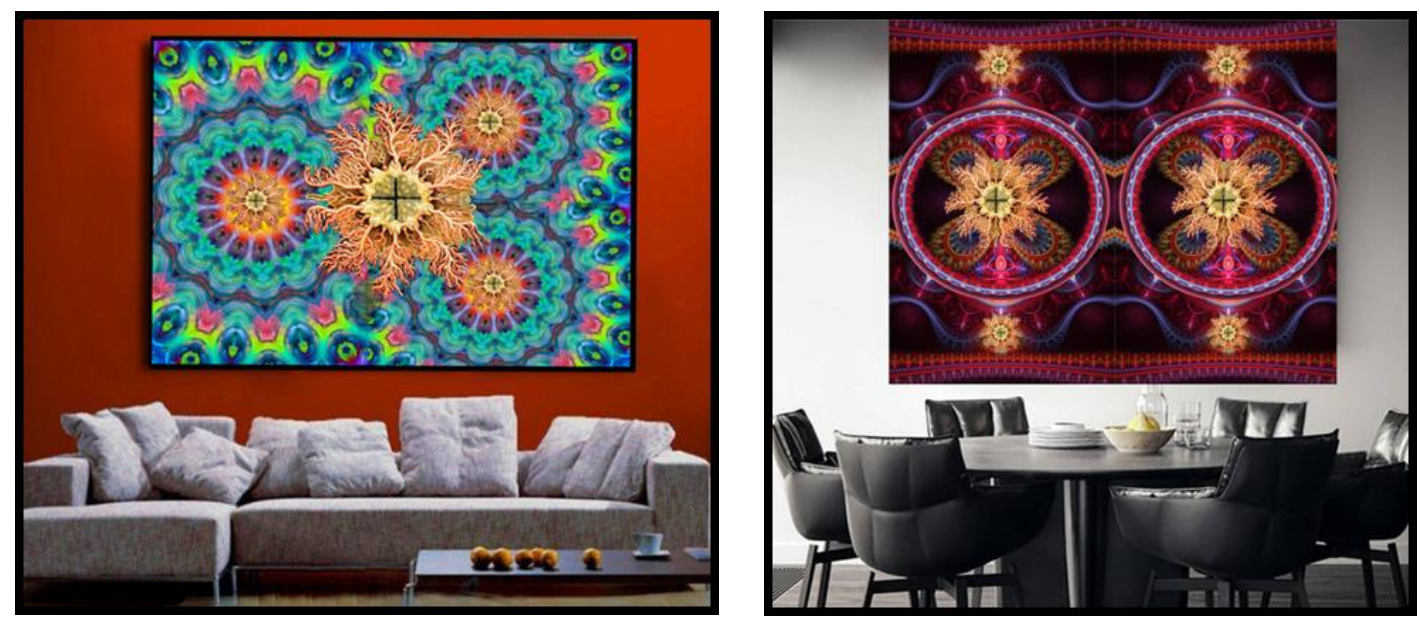

شكل ( 15) تصميمات مستوحاة النظام البنائي لهيئة الثعاعيات في الطبيعة باستخدام برامج الجرافيك و ويتضح ذلك من خلالة الحركات

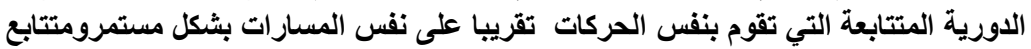
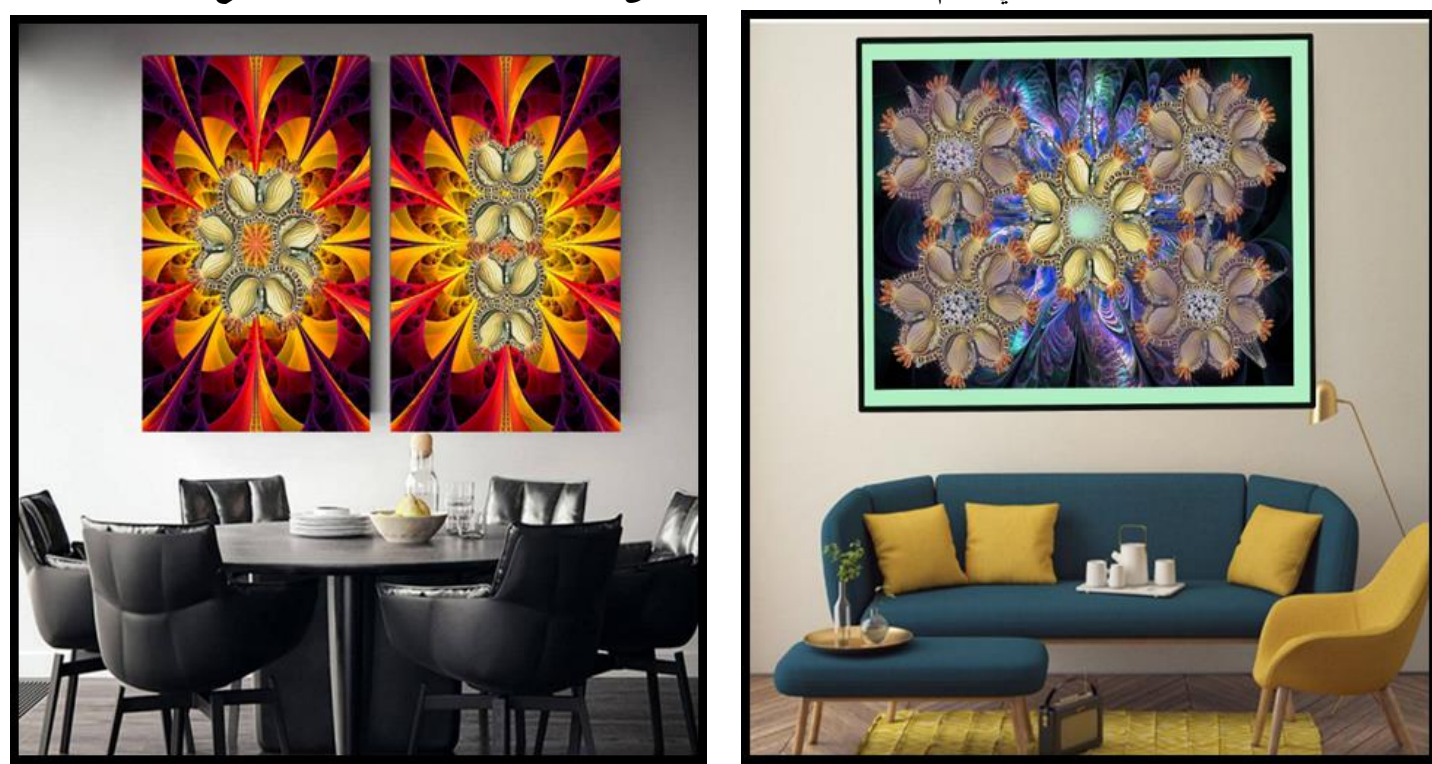

شكل (16 ) يتضح الاتزان والتتماثل مع التكبير والتصغير بين العناصر ويتضح من خلالة التشابهاه الذاتي في التصميم مع التتابع في الحركة

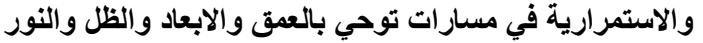
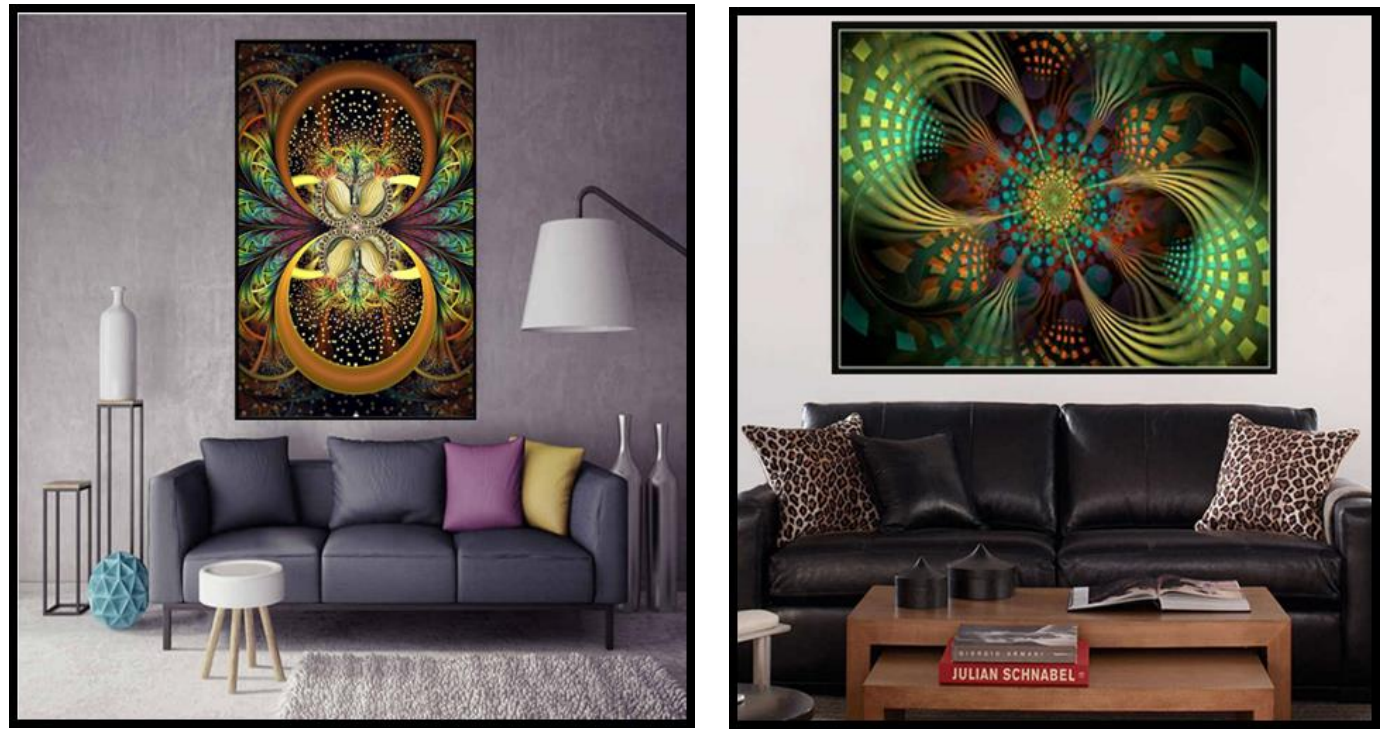

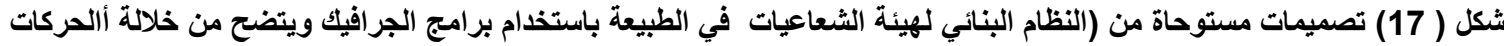

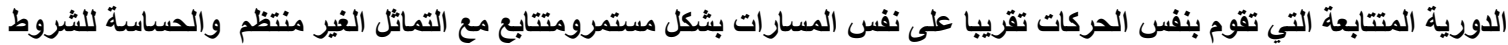

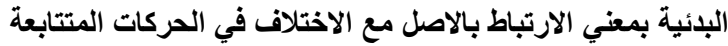



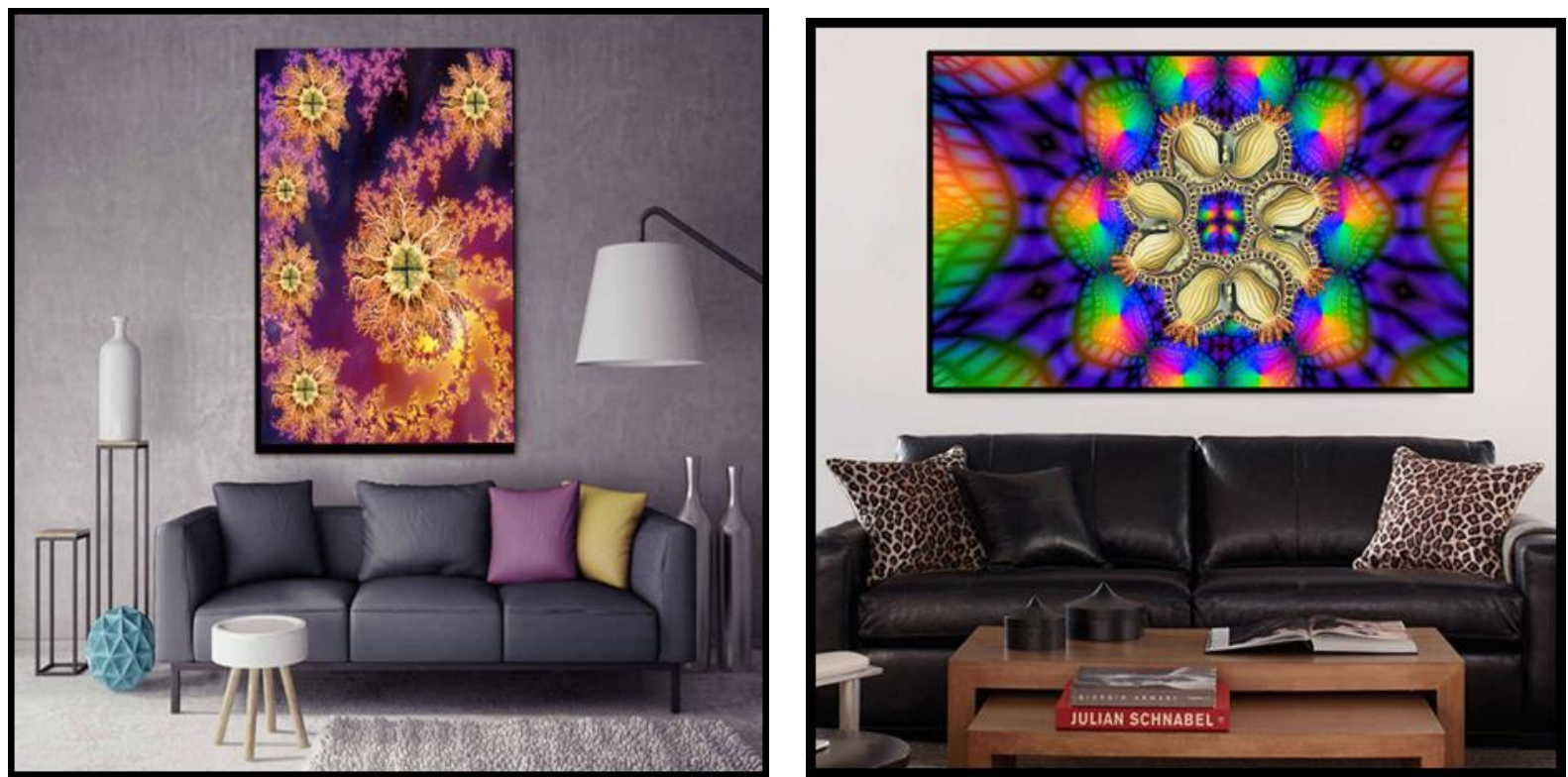

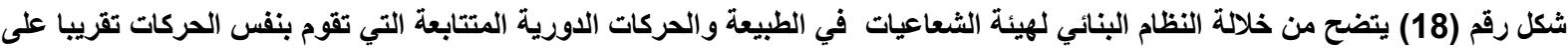

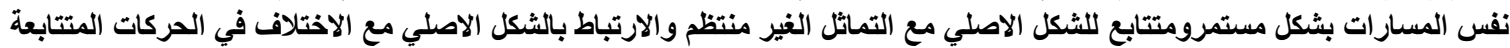

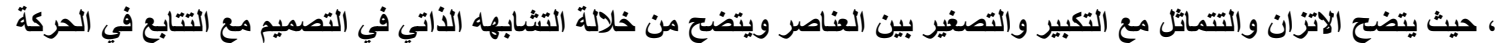
والاستمرارية
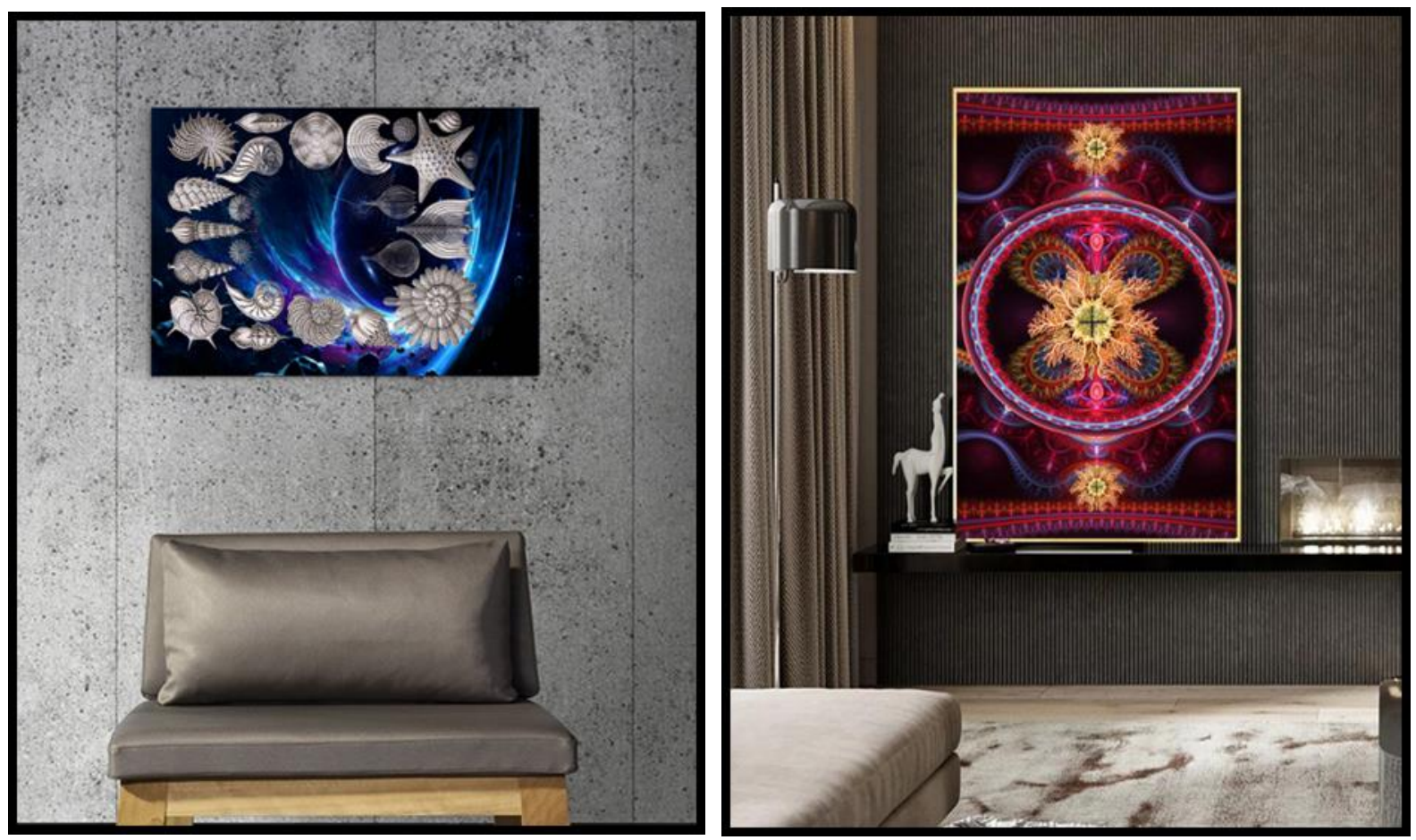

شكل ( 19) تصميمات مستوحاة من النظام البنائي لهيئة الثعاعيات في الطبيعة ويتضح فيها النظم الحركية النظام البنائي لهيئة الثعاعيات

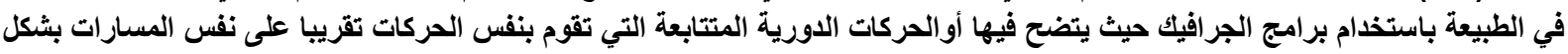

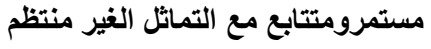


- دراسة النظم البنائية الثعاعية للعناصر في الطبيعة بوصفها نظام كلي متكامل يفتح مجالًا جديدًا في مجال التصميم الزخرفي. ـ تقدم الدر اسات العلمية المعاصرة حلو لا جديدة للبنية التصميمية للعناصرفي الطبيعية (النظم الثعاعية) مماحدث تطور

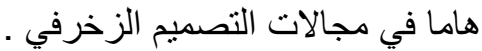
- إن هناك بدائل من الحلول التصميمة اللانهائية من خلال الصباغات البنائية للشعاعيات في الطبيعة تتحقق فيها القيم الوظيفية و الجمالية فى التصميم.

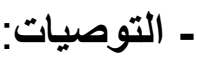
-- الاهتمام بالبنية البنائية الثكلية للشعاعيات في الطبيعة بوصفها نظام كلي متكامل يقوم علي اساسه صياغات تصميمية تشرى مجالى التصميم. -- فتح آفاق جديدة ورؤى تجريبية تتبنى حرية الإبداع في مجال التصميم الزخرفي من خلال استثمار النظم البنائية و الثكلية للشعاعيات في الطبيعة . -إجر اء المزيد من الأبحاث للشعاعيات في الطبيعة تقدم النظريات المعاصرة حلولا جديدة من خلال تتبع النظام البنائي للثتعاعيات في الطبيعة وماتتضمنة من قو انين نثابة وتقارب وتكر ار و تماتل وتقوم علي اساسها صياغات تصميمية مستحدثة وتتقدم الباحثة بجزيل الثكر والتقدير لعمادة الاراسات العليا والبحث العلمى بجامعة دارالعلوم، الرياض، المملكة العربية السعودية للاعم المادي لهزا البحث.

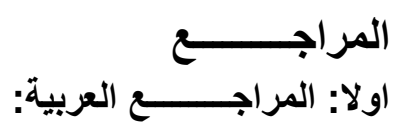
1- أحمد فتحى سيد أحمد: " الكيمياء الحيوية "، دار الفجر للنشر والتوزيع، القاهرة، 2002، ص ص203.

-Ahamed Fatthy Sayied Ahmaed: "Biochemistry", Dar Al-Foajr for Publieshing and Distribution, Cairo, 2002, p. 201.

2- حسينى على محمد عوض: " النظام الهندسى لعنصر النباتات تحت الجهرية كمدر لإثراء التصميمات الزخرفية "،

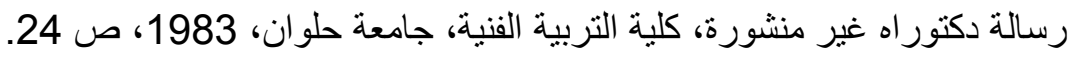

-Hosiny Ali mahmod awoad 'alnezam alhandasy "The geometric system for the submicroscopic plates and grass component as a source for enriching designs", published PhD thesis, Faculty of Art Education, Helwan University ،1983p.24

3- محمد حافظ الخولى: " النظم التحليلية لعنصر النباتات كمدخل تجريبى لتدريس التصميم"، رسالة دكتور اه غير منشورة،

$$
\text { كلية التربية الفنية، جامعة حلوان، 1986، صـ } 35 .
$$

-Muhamomad Haafez Al-Khoully: "Analytical Systeims of the Plantes Elemient as an Experimental Introduction to Design Teaching," unpublished $\mathrm{PhD}$ thesis, Faculty of Art Education, Helwan Unieversity, 1986, p 41

4-هربرت ريد: " تعريف الفن "، ترجمة: إبراهيم إمام ومصطفى الأرنؤوطى، دار النهضة العربية، 1962، ص 19. -Herird "Defining Art", translated by: Ibrehim amam and Mustafa Al-Arnaouti, Dar Alnada Alarnaaaoty 1962, p. 19. 


\section{ثانيا: المراجــــــع الاجنبية:}

5-Achim Menges: "Instrumental Geometry ", A-D Morphogenetic Design, Wiley Academy, 2005, p.20.

6-Akhavan, A.; Samsudin, A.; Akhshani, A".(01-10-2011) .A syemmetric imiage encryption scheeme based on combination of nonlinear chaotic maps "Journal of the Franklin

7-Nehmzow, Ulrich; Keith Walker (Dec 2005) .

8-Malcom, D.C.: "Design, Elements and Principles", Paris, Worcester, 1971, p.98.

E.H. Gombrich: "The Ring of Order", Phaide Press, New York, 1984, p.136.

9-Quantitateive description of robot-ennvironment interacteion using chaos theory) "PDF .(Robotics and Autonomous Syestems.

10-Wotherspoon, T.; Hubler, A. (2009). "Adapttation to the Eidge of Self-Adjusting Logistic Map ."The Journal of Phyesical Chemistry. 